\title{
Poly(3-hexylthiophene)-b-poly(3-cyclohexylthiophene): Synthesis, Microphase Separation, Thin Film Transistors, and Photovoltaic Applications
}

\author{
PEI-TZU WU, ${ }^{1,2}$ GUOQIANG REN, ${ }^{1,2}$ FELIX S. KIM, ${ }^{1,2}$ CHAOXU LI, ${ }^{3}$ RAFFAELE MEZZENGA, ${ }^{3,4}$ SAMSON A. JENEKHE \\ ${ }^{1}$ Department of Chemical Engineering, University of Washington, Seattle, Washington 98195-1750 \\ ${ }^{2}$ Department of Chemistry, University of Washington, Seattle, Washington 98195-1750 \\ ${ }^{3}$ Department of Physics and Fribourg Center for Nanomaterials, Fribourg University, Fribourg, Switzerland \\ ${ }^{4}$ Nestlé Research Center, Vers-Chez-Les-Blanc, 1000 Lausanne 26, Switzerland
}

\begin{abstract}
We report the synthesis, characterization, microphase separation, field-effect charge transport, and photovoltaic properties of regioregular poly(3-hexylthiophene)-bpoly(3-cyclohexylthiophene) (P3HT-b-P3cHT). Two compositions of $\mathrm{P} 3 \mathrm{HT}-b-\mathrm{P} 3 \mathrm{cHT}(\mathrm{HcH} 63$ and $\mathrm{HcH} 77)$ were synthesized with weight-average molecular weights of 155,500 and 210,800 and polydispersity indices of 1.45 and 1.57 , respectively. Solvent-casted $\mathrm{HcH} 77$ was found to self-assemble into nanowires with a width of $12.5 \pm 0.9 \mathrm{~nm}$ and aspect ratios of $50-120$, as observed by TEM imaging. $\mathrm{HcH} 77$ and $\mathrm{HcH} 63$ annealed $280{ }^{\circ} \mathrm{C}$ were observed by small angle X-ray scattering (SAXS) and wide angle X-ray scattering (WAXS) to be microphase-separated with characteristic length scales of 17.0-21.7 nm. The microphase-separated domains were shown to be crystalline with interlayer backbone (100) $d$-spacings of 1.69 and $1.40 \mathrm{~nm}$,
\end{abstract}

which correspond to the $\mathrm{P} 3 \mathrm{HT}$ and $\mathrm{P} 3 \mathrm{cHT}$ blocks, respectively. Field-effect transistors fabricated from $\mathrm{P} 3 \mathrm{HT}-b$ - $\mathrm{P} 3 \mathrm{cHT}$ thin films showed a mobility of holes $\left(0.0019 \mathrm{~cm}^{2} / \mathrm{Vs}\right)$ which is independent of thermal annealing. Bulk heterojunction solar cells based on $\mathrm{HcH} 77 /$ fullerene $\left(\mathrm{PC}_{71} \mathrm{BM}\right)$ blend thin films had a maximum power conversion efficiency of $2.45 \%$ under $100 \mathrm{~mW} / \mathrm{cm}^{2}$ AM1.5 solar illumination in air. These results demonstrate that all-conjugated block copolymers are suitable semiconductors for applications in field-effect transistors and bulk heterojunction solar cells. (C) 2009 Wiley Periodicals, Inc. J Polym Sci Part A: Polym Chem 48: 614-626, 2010

KEYWORDS: conjugated polymers; diblock copolymers; microphase separation; polymer solar cells; SAXS; thin-film transistors; WAXS
INTRODUCTION Multicomponent-conjugated polymer systems, ${ }^{1-26}$ especially polymer blends ${ }^{1-7}$ and block copolymers, ${ }^{8-20}$ offer the opportunity to tailor their electronic and optical properties to levels well beyond those possible in homopolymers and random/alternating copolymers. Most polythiophene-based multicomponent conjugated polymer systems investigated so far have been based on poly(3-hexylthiophene) (P3HT), ${ }^{1,27,28}$ which is known to be a high mobility p-type polymer semiconductor ${ }^{29,30}$ and a good donor component in fullerene-based bulk heterojunction (BHJ) solar cells. ${ }^{31,32}$ Although binary blends of poly(3-alkylthiophene)s, exemplified by blends of P3HT with poly(3-decylthiophene) $(\mathrm{P} 3 \mathrm{DT})^{1}$ or poly(3-octylthiophene) (P3OT), ${ }^{4}$ have interesting electronic properties and charge carrier mobility that vary with blend composition, ${ }^{1}$ random copolymers can have superior properties and more robust morphology. ${ }^{4}$ Random copolythiophenes with a variety of substituted side chains such as hexyl, octyl, cyclohexyl, or 4-octylphenyl have been reported. ${ }^{43-37}$ Because of their well-defined sequences, ordered chain architecture, and capability for self-assembly, block copolymers are especially attractive among multicomponent conjugated polymer systems. Block copolythiophenes with crystalline-amorphous diblock architecture incorporating poly(3-hexylthiophene) (P3HT) block have been reported. ${ }^{38-40}$ The presence of amorphous domains in polymer semiconductors is not desirable for many electronic applications such as thin film transistors and photovoltaic cells. ${ }^{41}$ To ensure crystallinity in microphase-separated domains, crystalline-crystalline diblock copolymers can be an appealing approach. ${ }^{41} \mathrm{How}$ ever, block copolythiophene systems have not yet been extensively studied and evaluated for electronic applications such as thin film transistors and photovoltaic cells. ${ }^{33-40}$

We report herein the synthesis, microphase separation, fieldeffect charge transport, and photovoltaic properties of regioregular poly(3-hexylthiophene)- $b$-poly(3-cyclohexylthiophene) (P3HT- $b$-P3cHT). Two compositions of P3HT- $b$-P3cHT, 
denoted HcH63 and HcH77, were found to undergo microphase separation into two distinct crystalline domains as observed by temperature-dependent small-angle and wideangle X-ray scattering (SAXS, WAXS). Bottom-contact fieldeffect transistors were fabricated and used to evaluate the carrier mobility of holes in P3HT- $b$-P3cHT thin films. Bulk heterojunction solar cells based on P3HT- $b$-P3cHT/fullerene blends were fabricated and used to study the photovoltaic properties of P3HT- $b$-P3cHT.

\section{EXPERIMENTAL}

\section{Materials}

3-Hexylthiophene, 2,5-dibromo-3-cyclohexylthiophene, anhydrous THF, isopropylmagnesium chloride $(i-\mathrm{PrMgCl}, 2 \mathrm{M}$ in THF), butylmagnesium chloride $(\mathrm{BuMgCl}, 2 \mathrm{M}$ in THF), [1,2-bis(diphenylphosphino)ethane]dichloronickel(II) [Ni (dppe) $\mathrm{Cl}_{2}$ ], $\mathrm{N}$-bromosuccinimide (NBS), and poly(3-hexylthiophene) were purchased from Sigma-Aldrich and were used as received. 2,5-Dibromo-3-hexylthiophene was synthesized following the literature method. ${ }^{41,42}[6,6]-$ phenyl- $\mathrm{C}_{71}$ butyric acid methyl ester $\left(\mathrm{PC}_{71} \mathrm{BM},>99.0 \%\right)$ was purchased from American Dye Source (Quebec, Canada) and used as received. 1,2-dicholorobenzene (ODCB, anhydrous, > 99\%, Aldrich) was degassed with nitrogen before use. Poly(3,4thylenedioxythiophene):poly(styrene sulfonate) (PEDOT; Baytron P VP AI 4083) was purchased from H. C. Stark (Newton, $\mathrm{MA}$ ) and passed through a $0.45-\mu \mathrm{m}$ filter before spin-coating.

\section{Polymer Synthesis \\ Poly(3-hexylthiophene)-block-poly(3-cyclohexylthiophene) (HcH63 \& HcH77)}

The molar feed ratio of 2,5-dibromo-3-hexylthiophene (HT) and 2,5-dibromo-3-cyclohexylthiophene (cHT) was 1:1 and 2:1 for the HcH63 and HcH77 samples, respectively. The molecular weight was controlled by fixing the ratio of the amount of $\mathrm{Ni}$ catalyst to the total monomer amount at 1:100. The typical synthesis procedure of $\mathrm{HcH} 63$ diblock copolymer (feed molar ratio of 1:1) was as follows: two roundbottomed flasks (250 mL) equipped with a three-neck stopcock were dried by heating under reduced pressure and cooled to room temperature. 2,5-Dibromo-3-hexylthiophene (1.038 g, $3.2 \mathrm{mmol}$ ) was placed in one flask under $\mathrm{Ar}$, and then evacuated under reduced pressure to remove any moisture and oxygen inside. After anhydrous THF (45 mL) was added into the flask via a syringe, the solution was stirred at $0{ }^{\circ} \mathrm{C} .2 \mathrm{M}$ solution of $i$-PrMgCl in THF $(1.6 \mathrm{~mL}, 3.2 \mathrm{mmol})$ was added via a syringe, and the mixture was stirred at $0{ }^{\circ} \mathrm{C}$ for $30 \mathrm{~min}$ (Solution 1). In the other flask, 2,5-dibromo-3cyclohexylthiophene $(1.032 \mathrm{~g}, 3.2 \mathrm{mmol})$ was first reacted with $i$-PrMgCl (1.6 mL, $3.2 \mathrm{mmol}$ ) (Solution 2) at $0{ }^{\circ} \mathrm{C}$ for 30 min, and then heated to $50{ }^{\circ} \mathrm{C}$. Solution 1 was heated up to $50{ }^{\circ} \mathrm{C}$ and $\mathrm{Ni}(\mathrm{dppe}) \mathrm{Cl}_{2}$ catalyst $(33.8 \mathrm{mg}, 0.064 \mathrm{mmol}$ ) was added in one portion. After stirring for $1 \mathrm{~h}$, Solution 2 was transferred to Solution 1 via a double-tipped needle, and the resulting solution was stirred at $50{ }^{\circ} \mathrm{C}$ for overnight. The reaction was quenched by adding $\mathrm{HCl}$ solution (20 wt \%) into the solution. The crude polymer was successively washed by Soxhlet extraction using methanol, acetone, and hexane. The solvent was removed by evaporation to give a purple solid (0.59 g, Yield: $55 \%$ ). HcH77 with a molar feed ratio of 2:1 (HT:cHT) was also synthesized following the same procedure to give a purple solid ( $0.8 \mathrm{~g}$, Yield: $65 \%)$ as the final product. The assignment of each proton resonance in the ${ }^{1} \mathrm{H}$ NMR spectra of $\mathrm{HcH}$ samples is as shown in Figure S1. Based on the integration of the peaks of the two resonance peaks of methyl groups in hexyl $(b)$ and cyclohexyl chains $\left(b^{\prime}\right)$, the actual molar ratios of the P3HT and P3cHT segments were calculated to be $63: 37$ and 77:23 for HcH63 and $\mathrm{HcH77}$, respectively. The composition ratio $(n: m)$ of $\mathrm{HcH}$ is calculated from the ratio of the integrated peak area of $b$ to the integrated peak area of $b^{\prime}$ (Figure S1); [ $n: m=$ (integration of $b / 2$ ):(integration of $\left.\left.b^{\prime}\right)\right]$. We note that the proton resonance at 3.05 and $2.82 \mathrm{ppm}$ are characteristic of $\alpha$-methylene protons in head-to-tail linkage of 3-alkylthiophene units whereas the proton resonance at $2.59 \mathrm{ppm}$ is characteristic of $\alpha$-methylene protons in head-to-head or tail-to-tail linkage shown in Figure S1.

HcH63: ${ }^{1} \mathrm{H}$ NMR $\left(\mathrm{CDCl}_{3}\right), \delta(\mathrm{ppm}): 7.05(0.37 \mathrm{H}), 7.0(0.63 \mathrm{H})$, $3.05-2.59(1.63 \mathrm{H}), 1.97-1.70(2.74 \mathrm{H}), 1.48-1.36(6 \mathrm{H}), 0.96$ (2.0H). Regioregularity of $\mathrm{HcH} 63$ was calculated to be 91.4\%.

HcH77: ${ }^{1} \mathrm{H}$ NMR $\left(\mathrm{CDCl}_{3}\right), \delta(\mathrm{ppm}): 7.05(0.23 \mathrm{H}), 7.0(0.77 \mathrm{H})$, $3.05-2.58(1.77 \mathrm{H}), 1.97-1.70(2.46 \mathrm{H}), 1.48-1.36(6 \mathrm{H}), 0.96$ (2.3H). Regioregularity of $\mathrm{HcH} 77$ was calculated to be $94.5 \%$.

\section{Poly(3-cyclohexylthiophene) (P3cHT)}

Butylmagnesium chloride (2 M solution in THF, $4.8 \mathrm{~mL}, 9.6$ mmol) was added into a solution of 2,5-dibromo-3-cyclohexylthiophene (3.16 g, $9.8 \mathrm{mmol})$ in anhydrous THF (40 mL) at 10-15 ${ }^{\circ} \mathrm{C}$, and purged with $\mathrm{N}_{2}$. The solution was degassed and purged upon stirring for $30 \mathrm{~min}$ at $10-15{ }^{\circ} \mathrm{C}$, then heated at mild reflux for $1 \mathrm{~h}$. Reflux is stopped before the addition of $\mathrm{Ni}(\mathrm{dppe}) \mathrm{Cl}_{2}(36.2 \mathrm{mg}, 0.068 \mathrm{mmol}$ ) and then the mixture was refluxed for at least $24 \mathrm{~h}$. The mixture was cooled to room temperature and poured into methanol to form a precipitate. The precipitate was filtered and washed with methanol and hexane, and further purified by Soxhlet extraction in hexane for 2 days. The product was dried in vacuum to yield a black solid. (Yield: $1.04 \mathrm{~g}, 64.6 \%) .{ }^{1} \mathrm{H}$ NMR ( $\left.\mathrm{CDCl}_{3}\right), \delta$ (ppm): $7.05(1 \mathrm{H}), 3.05(0.82 \mathrm{H}), 2.62$ (0.18), $1.97-1.80(4 \mathrm{H}), 1.28(4 \mathrm{H}), 0.9(2 \mathrm{H})$. Regioregularity was estimated to be $86 \%$. The polymer has very poor solubility in THF, chloroform, chlorobenzene, 1,2-dichlorobenzene, and etc. The number-average molecular weight $\left(M_{\mathrm{n}}\right)$ was determined to be $38,800 \mathrm{~g} / \mathrm{mol}$ with a polydispersity index of 2.99 by GPC analysis against polystyrene standards in chlorobenzene at $60^{\circ} \mathrm{C}$.

\section{Sample Preparation for TEM and AFM Imaging}

$\mathrm{HcH} 63$ or HcH77 (15 mg) was dissolved in $1 \mathrm{~mL}$ of degassed 1,2-dichlorobenzene (ODCB, Aldrich, anhydrous, 99\%) and magnetically stirred overnight at room temperature. The resulting solution was passed through a $1.0 \mu \mathrm{m}$ filter and allowed to stand for $24 \mathrm{~h}$. For TEM imaging, the solution was diluted 10 times with ODCB, drop-cast onto a TEM grid 
(300 mesh, carbon coated, copper grid, Electron Microscopy Sciences) and dried in a vacuum oven. For tapping modeAFM imaging, the dispersion was spin-coated onto a clean silicon wafer at $3000 \mathrm{rpm}$ and dried in a vacuum oven.

\section{Sample Preparation for WAXS and SAXS}

Thick films of HcH63 and HcH77 were first casted from chloroform solutions. The films were annealed at $280{ }^{\circ} \mathrm{C}$ under high vacuum for $12 \mathrm{~h}$, and then slowly cooled to room temperature, allowing recrystallization from the melt state.

\section{Characterization}

${ }^{1} \mathrm{H}$ NMR spectra were recorded on a Bruker-AF300 spectrometer at $300 \mathrm{MHz}$. UV-visible absorption spectra were recorded on a Perkin-Elmer model Lambda 900 UV/vis/ near-IR spectrophotometer. Spin-coated polymer thin films were prepared from 2 wt \% solutions in chloroform. The photoluminescence (PL) emission spectra were obtained with a Photon Technology International (PTI) model QM2001-4 spectrofluorimeter. The molecular weights reported for the polymers were determined on Polymer Lab Gel Permeation Chromatography (GPC) Model 120 (DRI, PLBV400HT Viscometer) against polystyrene standards in chlorobenzene at $60{ }^{\circ} \mathrm{C}$. Differential scanning calorimetry (DSC) scans were obtained on TA Instrument Q20 at a heating rate of $10^{\circ} \mathrm{C} / \mathrm{min}$.

\section{Small-Angle and Wide-Angle X-Ray Scattering}

Small angle X-ray scattering (SAXS) and wide angle X-ray scattering (WAXS) measurements were performed on an Anton-Paar SAXSess instrument. The fixed sample-to-detector distance $(265 \mathrm{~mm})$ and wavelength $(\lambda=0.1542 \mathrm{~nm})$ provide a comparably limited $q$-range of $0.2-10 \mathrm{~nm}^{-1}$. Here $q$ is the scattering vector defined as $q=4 \pi \sin (\theta) / \lambda$, with $2 \theta$ the scattering angle. The scattering signal was collected by highly sensitive imaging plates and treated by the SAXSquant software from Anton-Paar.

\section{Atomic Force Microscopy}

Atomic force microscopy (AFM) imaging was done with a Dimension 3100 Scanning Probe Microscope (Veeco Instruments, Woodbury, NY) operating in tapping mode. The films for atomic force microscopy imaging of surface morphology were spin-coated on a silicon wafer substrate.

\section{Transmission Electron Microscopy}

TEM images were acquired on an FEI Tecnai $G^{2}$ F20 TEM at $200 \mathrm{kV}$, with objective aperture to enhance the contrast. TEM images were acquired with a CCD camera and recorded with Gatan DigitalMicrograph ${ }^{\mathrm{TM}}$ software.

\section{Fabrication and Characterization of Field-Effect Transistor}

Bottom-contact and bottom-gate geometry was used to fabricate and test the field-effect transistors from the copolymers. Heavily $n$-doped silicon substrates acted as gate electrode and thermally grown silicon dioxide $\left(300 \mathrm{~nm}\right.$ thick; $C_{i}=11$ $\mathrm{nF} / \mathrm{cm}^{2}$ ) as gate insulator. Gold source and drain electrodes (50-nm thick) were patterned by photolithography with $\mathrm{Cr}$ adhesive layer $(\sim 2 \mathrm{~nm})$. Transistor channel has width $(W)$ of $800 \mu \mathrm{m}$ and length $(L)$ of $20 \mu \mathrm{m}$. Substrates were cleaned by ultrasonication with acetone and isopropyl alcohol, and purged with argon. Self-assembled monolayer of octyltrichlorosilane was deposited by vapor deposition. Thin-film was formed from copolymer solution $(4 \mathrm{mg} / \mathrm{mL}$ in dichlorobenzene) by spin-coating on substrates at $1000 \mathrm{rpm}$ for $120 \mathrm{~s}$, then dried under vacuum at room temperature overnight. Devices were annealed at $150{ }^{\circ} \mathrm{C}$ for $1 \mathrm{~h}$ under $\mathrm{Ar}$ atmosphere. The film thickness was $22-25 \mathrm{~nm}$.

Output $\left(I_{\mathrm{ds}}\right.$ vs. $\left.V_{\mathrm{ds}}\right)$ and transfer $\left(I_{\mathrm{ds}}\right.$ vs. $\left.V_{\mathrm{g}}\right)$ characteristics of the devices were measured on a Keithley 4200 semiconductor characterization system (Keithley Instruments, Cleveland, $\mathrm{OH})$. Fabrication and characterization of the transistors were done in air except drying and thermal treatment. Field-effect mobility was calculated from the standard equation for saturation region in metal-oxide-semiconductor field-effect transistors: $I_{\mathrm{ds}}=\mu(W / 2 L) C_{i}\left(V_{\mathrm{g}}-V_{\mathrm{t}}\right){ }^{2}$ where $I_{\mathrm{ds}}$ is drain-source current, $\mu$ is field-effect mobility, $W$ and $L$ are the channel width and length, $C_{i}$ is the capacitance per unit area of the gate insulator $\left(C_{i}=11 \mathrm{nF} / \mathrm{cm}^{2}\right), V_{\mathrm{g}}$ is the gate voltage, and $V_{\mathrm{t}}$ is the threshold voltage.

\section{Fabrication and Characterization of Photovoltaic Cells}

Patterned indium tin oxide (ITO) glass substrates (10 $\Omega$ per square, Shanghai B. Tree Tech. Consult, Shanghai, China) were cleaned stepwise by acetone, DI water and isopropyl alcohol in an ultrasonic bath. To fabricate the photovoltaic devices, a $50 \mathrm{~nm}$ PEDOT buffer layer was spin-coated on top of ITO substrate at $3000 \mathrm{rpm}$ for $30 \mathrm{~s}$ and dried at $150{ }^{\circ} \mathrm{C}$ for $10 \mathrm{~min}$ under vacuum. The blend solutions for active layers were prepared by mixing the polymer $(\mathrm{HcH} 63$ or HcH77) with [6,6]-phenyl- $\mathrm{C}_{71}$ butyric acid methyl ester $\left(\mathrm{PC}_{71} \mathrm{BM}\right)$ and stirred in anhydrous ODCB $(30 \mathrm{mg} / \mathrm{mL}, 1: 1$ wt:wt), followed by filtration through a $0.45 \mu \mathrm{m}$ membrane. To prepare blends with different compositions, polymer-to$\mathrm{PC}_{71} \mathrm{BM}$ weight ratios were kept at 1:0.5, 1:0.75, 1:1, and 1:1.25, respectively. The blends were spin-coated in a $\mathrm{N}_{2}$ glovebox for $30 \mathrm{~s}$ to make thin films with $85-120 \mathrm{~nm}$ thickness measured by an Alpha-Step 500 profilometer (KLA-Tencor, San Jose, CA).

Post-treatments of active layers include "film aging" (kept in a closed Petri dish for a certain period of time) and "thermal annealing" (heat treatment on a hot plate for a certain period of time). The as-spin-coated active layer was treated under four conditions. (Condition 1: open dried in glovebox; Condition 2: film aging in a Petri dish until color changes and vacuum dried at $60{ }^{\circ} \mathrm{C}$; Condition 3: film aging in a Petri dish until color changes and thermally annealed at $110{ }^{\circ} \mathrm{C}$ for $5 \mathrm{~min}$. Condition 4: film aging in a Petri dish for $30 \mathrm{~min}$ and thermally annealed at $110{ }^{\circ} \mathrm{C}$ for $30 \mathrm{~min}$.) For composition dependence, the active layers were all treated at Condition 2. The substrates were then loaded into a thermal evaporator (BOC Edwards, 306) for the deposition of the cathode materials. $1.0 \mathrm{~nm} \mathrm{LiF}$ and $80 \mathrm{~nm}$ Al layers were sequentially deposited through a shadow mask on top of the active layer under high vacuum $\left(8 \times 10^{-7}\right.$ Torr $)$.

Each substrate contained five solar cell devices with an active area of $3.57 \mathrm{~mm}^{2}$. Current-voltage characteristics of 
SCHEME 1 Synthesis of Regioregular Poly(3-hexylthiophene)- $b$ poly(3-cyclohexylthiophene).

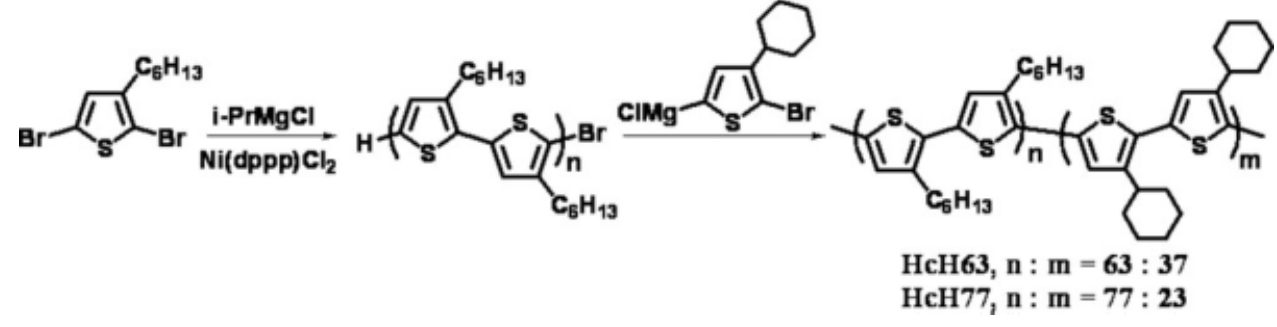

solar cells were measured using a HP4155A semiconductor parameter analyzer (Yokogawa Hewlett-Packard, Tokyo) in laboratory ambient air condition. A silicon diode (S1787-04, Hamamatsu), calibrated at the National Renewable Energy Lab (NREL, Golden, Colorado), was used to calibrate the filtered Xe lamp. A $100 \mathrm{~mW} / \mathrm{cm}^{2} 1.5 \mathrm{AM}$ sunlight illumination was simulated for solar cell testing.

The nanoscale morphology in the $\mathrm{HcH}: \mathrm{PC}_{71} \mathrm{BM}$ blend (active layer) thin films was characterized by TEM. To obtain the thin films, the solar cell devices were scratched and soaked in DI water until thin films could be peeled off the substrates. The thin films were then supported on TEM grids (carbon-coated 300 mesh copper grids, Electron Microscopy Sciences) and dried in a vacuum oven overnight. Selected area electron diffraction (SAED) was obtained by using selected area aperture (SAA) with a diameter of $200 \mu \mathrm{m}$ $\left(0.031 \mathrm{~mm}^{2}\right)$ and proper exposure time. AFM imaging was performed on the solar cell devices and an area of $5 \times 5$ $\mu \mathrm{m}^{2}$ on the sample was scanned to study topography and phase on the surface of $\mathrm{HcH}: \mathrm{PC}_{71} \mathrm{BM}$ blend films. UV-visible absorption spectra were recorded on the blend films spincoated on top of PEDOT/ITO substrates, following the same drying conditions as the corresponding photovoltaic devices.

\section{RESULTS AND DISCUSSION}

\section{Synthesis of Poly(3-hexylthiophene)- b-poly(3-cyclohexylthiophene)}

Synthesis of the diblock copoly(3-alkylthiophene)s and the homopolymer poly(3-cyclohexylthiophene) (P3cHT) was carried out by a modified Grignard metathesis method $(\mathrm{GRIM})^{41,42,43}$ as illustrated in Scheme 1. The P3HT block was first synthesized by polymerization of 2,5-dibromo-3hexylthiophene, followed by the addition of activated 2,5dibromo-3-cyclohexylthiophene monomer solution, resulting in the diblock copolymer, P3HT- $b$-P3cHT. Two compositions, denoted HcH63 and HcH77, were synthesized by using the molar feed ratios of 2,5-dibromo-3-hexylthiophene to 2,5dibromo-3-cyclohexylthiophene of $1: 1$ and 2:1, respectively. The actual compositions of $\mathrm{HcH} 63$ and $\mathrm{HcH} 77$ were determined from the ${ }^{1} \mathrm{H}$ NMR spectra (Figure S1), based on the $\alpha$ methylene protons of the hexyl and cyclohexyl side chains which showed resonances at 2.82 and $3.05 \mathrm{ppm}$, respectively. HcH63 consists of $63 \mathrm{~mol} \%$ of P3HT block and $37 \mathrm{~mol} \%$ of P3cHT block. Similarly, HcH77 is composed of 77 mol \% of P3HT block and 23 mol \% of P3cHT block. So, contrary to the feed ratio the actual compositions revealed a more P3HT block in $\mathrm{HcH} 63$ and $\mathrm{HcH} 77$. The main reason for this is the poorer solubility of the P3cHT block in the polymerization solvent (THF). Efforts to make other compositions with a greater P3cHT fraction failed. The regioregularity was determined to be 91.4 and $94.5 \%$ for $\mathrm{HcH} 63$ and HcH77, respectively, based on the resonance of the $\alpha$-methylene protons. ${ }^{42}$

The weight-average molecular weight $\left(M_{\mathrm{w}}\right)$ of $\mathrm{HcH63}$ and HcH77 was 155,500 and $210,800 \mathrm{~g} / \mathrm{mol}$, with a polydispersity index (PDI) of 1.45 and 1.57, respectively, determined by gel permeation chromatography (GPC) analysis with polystyrene standards. The GPC traces of the polymers at each step of the block copolymerization are shown in Figure S2 for HcH63. The number-average molecular weights measured by GPC $(107,240 \mathrm{~g} / \mathrm{mol}$ for HcH63 and 134,260 g/mol for $\mathrm{HcH77)}$ seem to be much higher than expected $M_{\mathrm{n}}$ from the monomer-to-Ni catalyst ratio $(100: 1)$ and this can be explained by over-estimation of measured $M_{\mathrm{n}}$ of poly(3alkylthiophene)s against polystyrene standards. ${ }^{44}$ Although the polydispersity index (1.45-1.57) is quite large compared to conventional block copolymers, it is however similar to that reported for other all-conjugated block copolymers such as poly(3-hexylthiophene)- $b$-poly(3-dodecylthiophene). ${ }^{43}$ One possible way to improve the polydispersity is by using asymmetric monomers such as 2-bromo-5-iodo-3alkylthiophene $\mathrm{e}^{38-40}$ and followed by rigorous purification. ${ }^{45,46} \mathrm{HcH} 63$ has a lower degree of regioregularity (91.4\%) because of the larger P3cHT block fraction. The bulky cyclohexyl side chains appear to hinder the head-totail linkage during chain-growth polymerization. ${ }^{35}$ Attempts to synthesize P3HT- $b$-P3cHT with a longer block of P3cHT by using HT:cHT ratios of $1: 2$ and $1: 4$ were unsuccessful, due to the difficulty in the growth of the P3cHT block that quickly precipitated from solution during polymerization.

Differential scanning calorimetry (DSC) scans of P3cHT homopolymer and P3HT- $b$-P3cHT samples are shown in Figure 1. P3HT has a reported $T_{\mathrm{m}}$ of $240-245{ }^{\circ} \mathrm{C},{ }^{28}$ whereas P3cHT (77\% regioregularity, $\mathrm{FeCl}_{3}$ oxidation polymerization) was reported to have a $T_{\mathrm{m}}$ of $280-300{ }^{\circ} \mathrm{C} .{ }^{37}$ A clear melting transition $\left(T_{\mathrm{m}}\right)$ and corresponding recrystallization transition $\left(T_{\mathrm{c}}\right)$ were observed in $\mathrm{P} 3 \mathrm{cHT}$ at $386{ }^{\circ} \mathrm{C}$ and $358{ }^{\circ} \mathrm{C}$, respectively. The much higher $T_{\mathrm{m}}$ observed in our sample of P3cHT is a result of both the higher regioregularity and higher molecular weight compared to the literature value. ${ }^{37}$ Two distinct $T_{\mathrm{m}}$ values and their corresponding $T_{\mathrm{c}}$ values were seen in the block copolymer samples $\mathrm{HcH} 63$ and $\mathrm{HcH} 77$. HcH63 showed $T_{\mathrm{m}}$ values of 214 and $363{ }^{\circ} \mathrm{C}$ and $T_{\mathrm{c}}$ values of 178 and $276{ }^{\circ} \mathrm{C}$, whereas $\mathrm{HcH} 77$ had $T_{\mathrm{m}}$ values of 220 and 

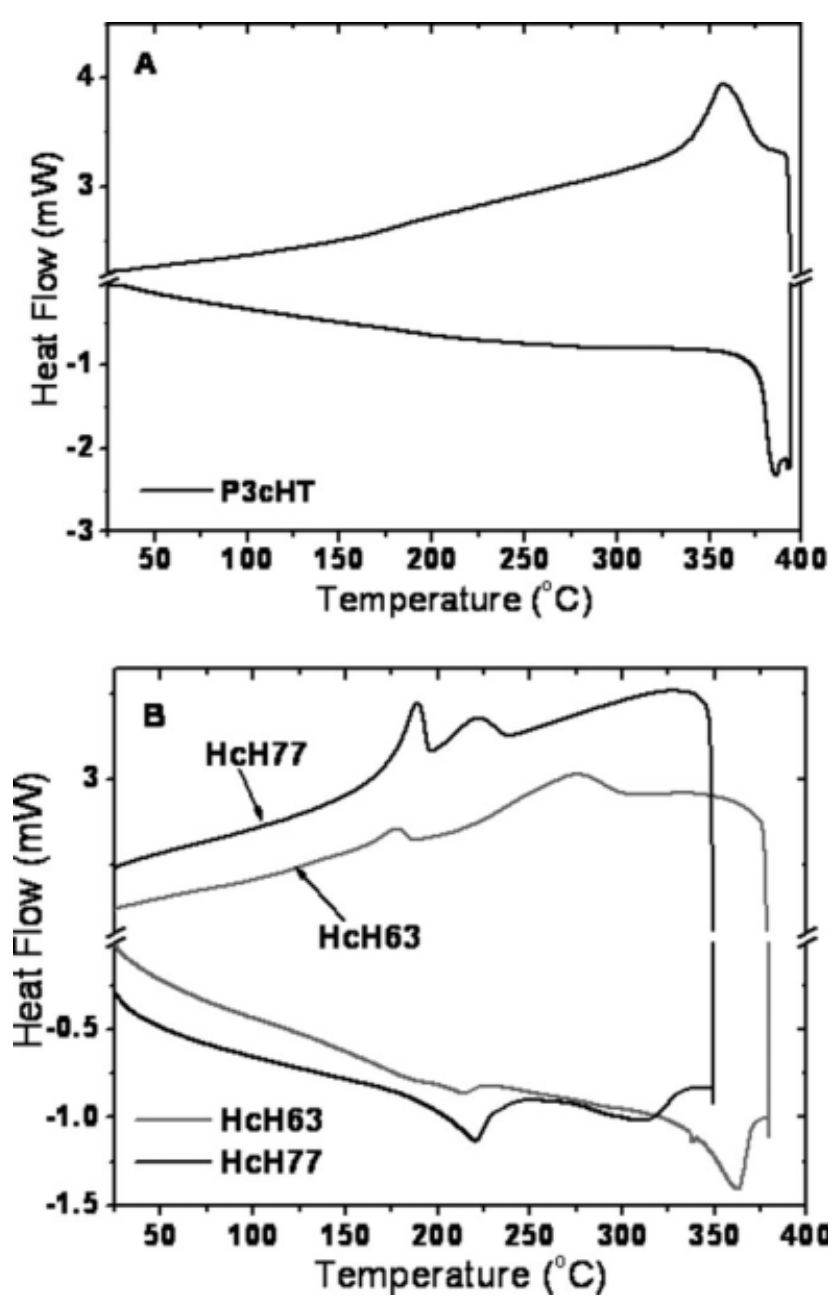

FIGURE 1 (A) The second heating DSC scan of P3cHT. (B) The second heating DSC scans of $\mathrm{HcH} 63$ and $\mathrm{HcH} 77$.

$310{ }^{\circ} \mathrm{C}$ and $T_{\mathrm{c}}$ values of 189 and $223^{\circ} \mathrm{C}$. The lower $T_{\mathrm{m}}$ value observed in the DSC scans of each $\mathrm{HcH}$ block copolymer sample is due to the P3HT block while the higher $T_{\mathrm{m}}$ value arises from the P3cHT block. The melting transition of the P3HT block in the block copolymers increases from $214{ }^{\circ} \mathrm{C}$ in $\mathrm{HcH} 63$ to $220{ }^{\circ} \mathrm{C}$ in $\mathrm{HcH} 77$, which is lower than 240-245 ${ }^{\circ} \mathrm{C}$ observed in the homopolymer P3HT. ${ }^{28,47}$ Similarly, the melting transition of the P3cHT block in the block copolymers decreases from $363{ }^{\circ} \mathrm{C}$ in $\mathrm{HcH} 63$ to $310{ }^{\circ} \mathrm{C}$ in $\mathrm{HcH77}$, which is lower than $386^{\circ} \mathrm{C}$ seen in the $\mathrm{P} 3 \mathrm{cHT}$ homopolymer. The increase of the $T_{\mathrm{m}}$ of each block with increasing amount of that block in the $\mathrm{HcH}$ diblock copolymer can be understood in terms of effects of molecular weight and purity on melting transition. These results also confirm the block architecture nature of the $\mathrm{HcH}$ samples as observed in other block copolymer systems. ${ }^{40,48}$

\section{Photophysical Properties}

The optical absorption spectra of dilute solutions $(1.0 \times$ $\left.10^{-6} \mathrm{M}\right)$ of $\mathrm{HcH} 63$ and $\mathrm{HcH77}$ in chloroform and as spincoated thin films are shown in Figure 2(A). In chloroform solution, HcH63 and $\mathrm{HcH77}$ had an absorption maximum $\left(\lambda_{\max }\right)$ at $469 \mathrm{~nm}$ and $453 \mathrm{~nm}$ that is similar to the broad and featureless absorption of $\mathrm{P}_{\mathrm{HTT}}{ }^{6}$ Surprisingly, P3cHT in dilute chloroform solution $\left(1.0 \times 10^{-6} \mathrm{M}\right)$ showed an absorption maximum at $505 \mathrm{~nm}$ and two shoulders at 550 and $610 \mathrm{~nm}$, suggesting the formation of aggregates in solution. Thin films of $\mathrm{HcH} 63$ and $\mathrm{HcH77}$ have an identical absorption maximum at $519 \mathrm{~nm}$ and shoulder peaks at 550 and $605 \mathrm{~nm}$ that are very similar to the P3HT homopolymer. $^{6}$ Thin film of P3cHT showed an absorption maximum at $512 \mathrm{~nm}$ and two shoulders at 554 and $613 \mathrm{~nm}$, which is more red-shifted compared to that of the film of P3cHT with lower degree regioregularity $\left(\lambda_{\max }: 422 \mathrm{~nm}\right) .{ }^{37}$ We note that the 605-nm shoulder peak in the absorption spectra of HcH63 and HcH77 films is associated with crystallinity resulting from strong intermolecular interactions $(\pi-\pi$ stacking) among regioregular poly(3-alkylthiophene) main chains, in contrast to the blue-shifted absorption seen in regiorandom poly(3-alkylthiophene)s. ${ }^{28}$ The optical band gap $\left(E_{\mathrm{g}}^{\text {opt }}\right)$ of HcH63 and $\mathrm{HcH77}$ estimated from the thin-film absorption edge is $1.91-1.92 \mathrm{eV}$, which is similar to that of P3HT. $^{28}$

In Figure 2(B), an identical photoluminescence (PL) emission maximum at $578 \mathrm{~nm}$ was observed from the PL spectra of
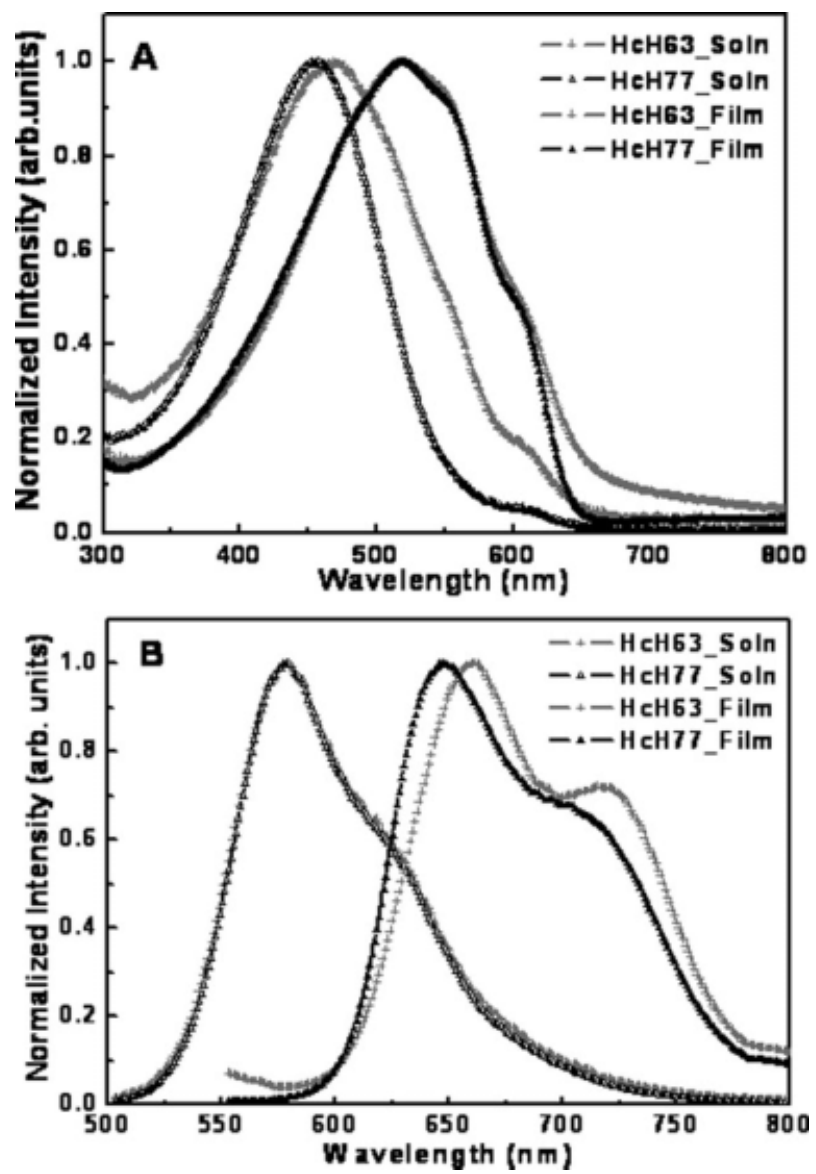

FIGURE 2 Optical absorption (A) and photoluminescence (B) spectra of $\mathrm{HcH} 63$ and $\mathrm{HcH77}$ in chloroform solutions and as thin films on glass substrates. 
HcH63 and HcH77 solutions in chloroform, which is close to the $570 \mathrm{~nm}$ maximum observed in poly(3-alkylthiophene)s, corresponding to the onset of $\pi-\pi^{*}$ transition of the absorption spectra. ${ }^{28,36}$ However, no detectable PL emission was obtained from P3cHT solution in chloroform. HcH63 and HcH77 thin films had PL emission maxima at 646-661 nm with shoulder peaks at $710-720 \mathrm{~nm}$ which is similar to P3HT. P3cHT thin film had a PL emission maxima at 711 $\mathrm{nm}$, which is much red-shifted compared to the 574-nm emission peak observed in a P3cHT sample with a lower degree of regioregularity. ${ }^{36}$ The bulky side chains of P3cHT account for the very similar absorption or photoluminescence spectra in solution and as thin films. ${ }^{36}$ On the contrary, P3HT has been known to show a red-shifted absorption and PL emission spectra in the solid state due to the improved electron delocalization in the solid state and good intermolecular ordering in a semicrystalline conjugated polymer. ${ }^{28}$ With the attachment of the P3HT block to the P3cHT block, the resulting interchain interaction was improved, which results in the observed red-shifted absorption and PL emission in the thin films of P3HT- $b$-P3cHT.

\section{Microphase Separation and Crystallinity}

To investigate the melt-phase behavior and solid-state morphology of HcH63 and HcH77, films spin-casted from chloroform solutions and annealed at $280{ }^{\circ} \mathrm{C}$ under high vacuum $\left(10^{-7}\right.$ mbar, for $\left.12 \mathrm{~h}\right)$ were characterized by wide-angle $\mathrm{X}$ ray scattering (WAXS) and small-angle X-ray scattering (SAXS). Figure 3(A) shows the WAXS spectra of HcH63 and $\mathrm{HcH77}$ and their parent homopolymers, P3HT and P3cHT. Both P3HT and P3cHT exhibit a distinct peak at 3.77 and $4.54 \mathrm{~nm}^{-1}$, respectively. The corresponding $d_{100}$ spacing values observed for P3HT and P3cHT, which are known as the interlayer stacking distance in the crystalline lamellar structure, are 1.67 and $1.38 \mathrm{~nm}$, respectively. The $1.67-\mathrm{nm}$ spacing is known as the interlayer stacking distance in the crystalline lamellar structure of P3HT. The 1.67-nm $d_{100}$ value seen in P3HT based on WAXS is very close to the reported $d_{100}$ of $1.64 \mathrm{~nm}$ from X-ray diffraction. ${ }^{28}$ For the diblock copolythiophenes $\mathrm{HcH} 63$ and $\mathrm{HcH77}$, two scattering vectors in the low- $q$ region $\left(q=3.72\right.$ and $\left.4.48 \mathrm{~nm}^{-1}\right)$ are seen in Figure $3(\mathrm{~A})$, corresponding to the two real-space $d_{100}$ distances of $1.69 \mathrm{~nm}\left(d_{\mathrm{P} 3 \mathrm{HT}}\right)$ and $1.40 \mathrm{~nm}\left(d_{\mathrm{P} 3 \mathrm{cHT}}\right)$, respectively. The relative reflection intensity $I\left(q^{\mathrm{P} 3 \mathrm{HT}}\right) / I\left(q^{\mathrm{P} 3 \mathrm{cHT}}\right)$ correlates with the P3HT/P3cHT block compositions directly. The $d_{100}$ distance $(1.69 \mathrm{~nm})$ of the P3HT block is consistent with the model where hexyl side chains are extended and the other smaller $d_{100}$ distance, $1.40 \mathrm{~nm}$, is characteristic of the P3cHT block. The SAXS spectra of HcH63 and HcH77 films, similarly annealed at $280{ }^{\circ} \mathrm{C}$ are shown in Figure 3(B). A distinct reflection peak at a scattering vector of $0.38 \mathrm{~nm}^{-1}$ is observed in the HcH63 diblock copolymer, corresponding to real space feature of $17.0 \mathrm{~nm}$. Similarly, the low- $q$ reflection peak at $0.31 \mathrm{~nm}^{-1}$ observed in the $\mathrm{HcH} 77$ corresponds to real space distance of $21.7 \mathrm{~nm}$. The increase in period from $\mathrm{HcH} 63$ to $\mathrm{HcH77}$ is consistent with their molecular weights.

The presence of a peak in the low $q$ region for the two block copolymers may arise from two different sources: (i) micro-
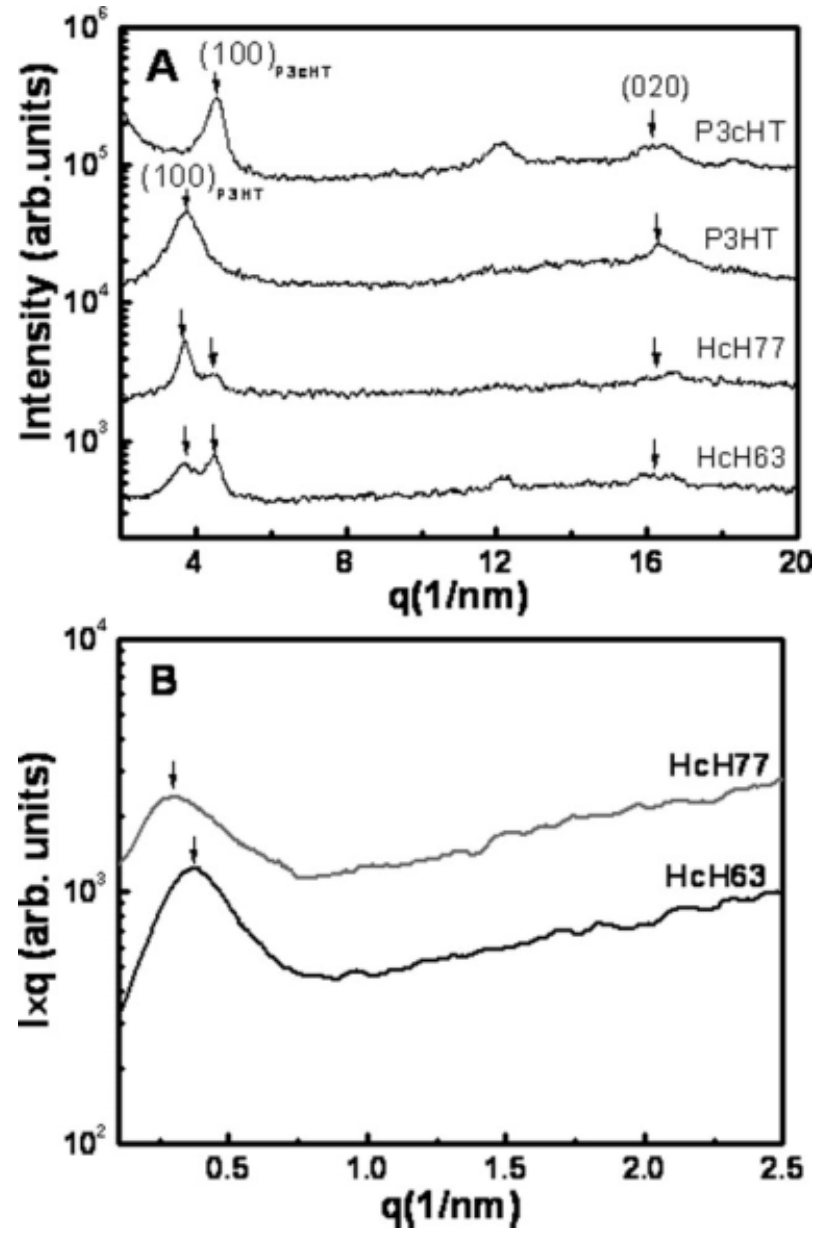

FIGURE 3 (A) WAXS spectra of two homopolymers (P3HT and $\mathrm{P} 3 \mathrm{cHT})$ and two diblock copolymers $(\mathrm{HcH} 63$ and $\mathrm{HcH} 77)$. (B) SAXS spectra of $\mathrm{HcH} 63$ and $\mathrm{HcH} 77$.

phase separation or (ii) density fluctuations observed above an order-disorder transition, also known as correlation hole. The presence of a correlation hole may be ruled out because the extremely low contrast in scattering lengths between P3HT and P3cHT (the two blocks have identical elemental composition, but different architectures) would lead to vanishing small scattering intensities. Furthermore, the crystallinity of the blocks is expected to quench density fluctuations. Finally, the decay slope of the $I(q)$ vs $q$ (not shown here) is consistent with a $q^{-3}$ slope, rather than the $q^{-2}$ behavior expected for a correlation hole.

Therefore, combined with the WAXS results from Figure 3(A), these SAXS results strongly support a solid-state assembly of P3HT- $b$-P3cHT into microphase-separated structures with two crystalline domains bearing characteristics of the two different side chains.

Nonetheless, the peak broadness and the $q^{-3}$ decay of the SAXS reflections suggest that the interfaces among microphase-separated domains must be very broad, as compared to perfectly sharp interfaces exhibiting a $q^{-4}$ Porod decay behavior. This is somewhat to be expected for two blocks, 

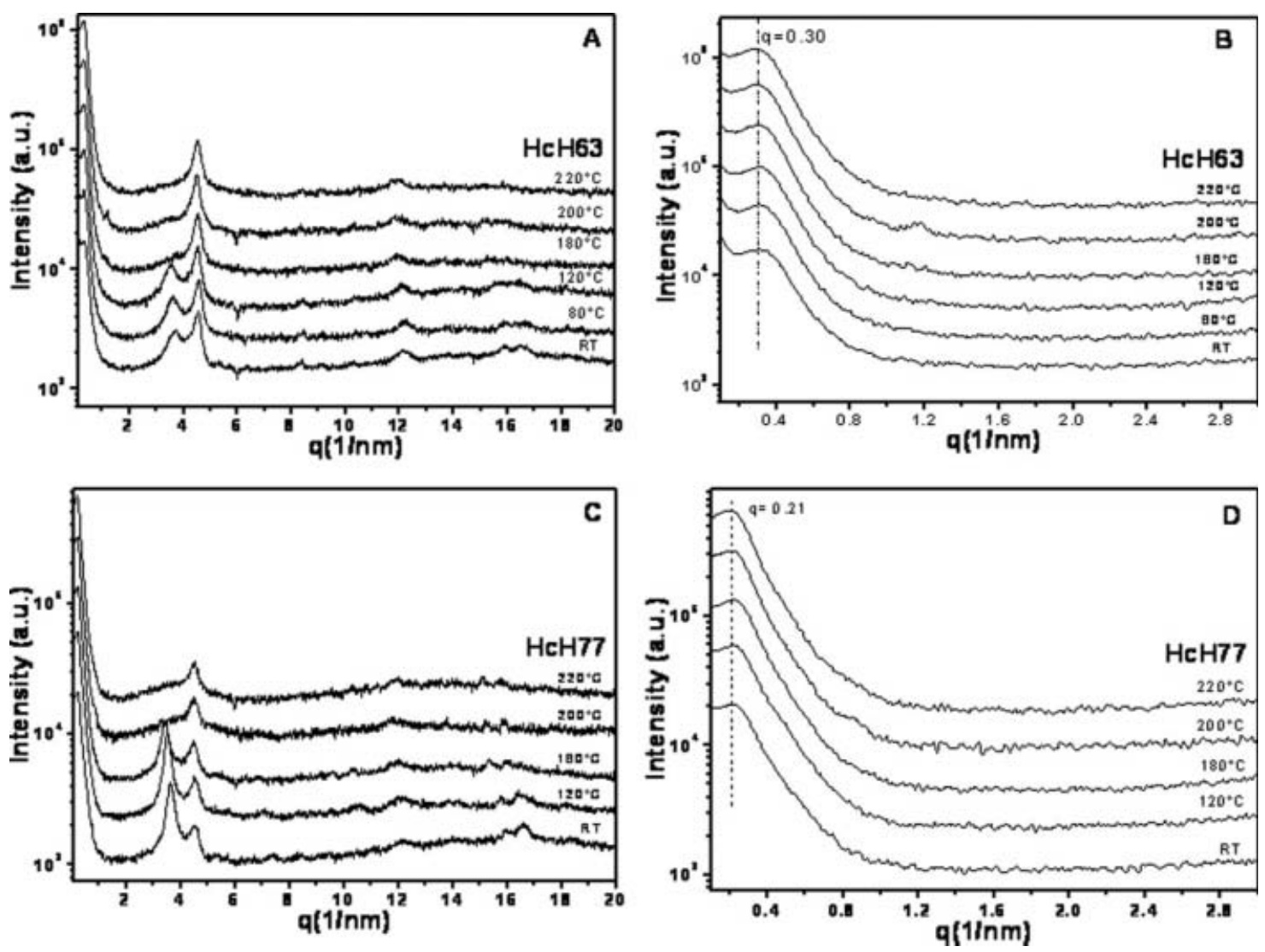

FIGURE 4 Temperature-dependent WAXS and SAXS spectra of HcH63 (A,B) and HcH77 (C,D), respectively.

P3HT and P3cHT, which due to their chemical similarities can only be in a very weakly segregated phase separation regime.

Finally, we note that the period measured by SAXS is consistently smaller than the corresponding contour lengths of the block copolymers estimated from their molecular weights. This implies either a tilted smectic $\mathrm{C}$ structure for the microphase separated domains (as expected in similar semicrystalline all-conjugated block copolythiophenes ${ }^{38}$ ) or a great amount of folding of the chains can also occur. A schematic molecular packing for the P3HT and P3cHT blocks is given in the Supporting Information (Figure S3). The temperaturedependent WAXS and SAXS scans of HcH63 and $\mathrm{HcH77}$ with increasing temperature from room temperature to $220{ }^{\circ} \mathrm{C}$ are shown in Figure 4. In the case of HcH63, one of the (100) WAXS reflection corresponding to the P3HT block has gradually decreased with temperature, diminishing into the background signal as the temperature was raised to $180{ }^{\circ} \mathrm{C}$ [Fig. 3(A)]. The temperature-dependent presence of the (100) reflection of the P3HT block was observed as the temperature approaches the melting transition of the P3HT block. Similarly, the WAXS scans of HcH77 in Figure 4(C) also show that the (100) reflection of the P3HT blocks is steadily reduced with increasing temperature and finally disappears when the temperature is raised to $200{ }^{\circ} \mathrm{C}$. The transition of the (100) reflection of the P3HT domain, $q^{\text {P3HT, }}$ observed in temperature-dependent WAXS scans of HcH63 $\left(\sim 180{ }^{\circ} \mathrm{C}\right)$ and HcH77 $\left(\sim 200^{\circ} \mathrm{C}\right)$ in Figure $4(\mathrm{~A}, \mathrm{C})$ is coherent with the onset of their melting transition seen in the DSC scans (Fig. 1), where HcH77 exhibits a higher $T_{\mathrm{m}}$ $\left(219^{\circ} \mathrm{C}\right)$ than $\mathrm{HcH} 63\left(206^{\circ} \mathrm{C}\right)$. The corresponding temperature-dependent SAXS scans in Figure 4(B,D) for HcH63 and $\mathrm{HcH77}$, respectively, show that the low- $q$ reflection peaks and thus microphase separation survive up to temperatures beyond the melting transition of P3HT.

\section{Solid-State Morphology}

TEM images of drop-cast films from $\mathrm{HcH} 63$ and $\mathrm{HcH77}$ solutions from 1,2-dichlorobenzene are shown in Figure 5. HcH63 shows a nanoscale morphology [Fig. 5(A)], whereas HcH77 appears as polymer nanowires with an average width of $12.5 \pm 0.9 \mathrm{~nm}$ and aspect ratios of $50-120$ in Figure 5(B). This is similar to the parent homopolymer $\mathrm{P}_{3 \mathrm{HT}}{ }^{49}$ other poly (3-alkylthiophene)s, ${ }^{49-51}$ and poly(3-butylthiophene)- $b$-poly (3-octylthiophene), ${ }^{41}$ crystalline polymer chains, which also undergo self-organization into nanowires from solution governed by strong $\pi-\pi$ stacking interactions.

The spin-coated diblock copolymer thin films on Si substrate in the fabrication of thin-film transistors were investigated after thermal annealing $\left(150{ }^{\circ} \mathrm{C}, 1 \mathrm{~h}\right)$ by $\mathrm{AFM}$, as shown in Figure 6. The surface morphology is very similar with average surface roughness of $1.2 \mathrm{~nm}$ and $1.3 \mathrm{~nm}$ for $\mathrm{HcH} 63$ and $\mathrm{HcH77}$, respectively. The domain sizes seen in Figure 6(A,C) are slightly larger than those observed from the thin films 
FIGURE 5 TEM images of (A) $\mathrm{HcH} 63$ and (B) $\mathrm{HcH} 77$ films drop-cast from solutions in 1,2dichlorobenzene.
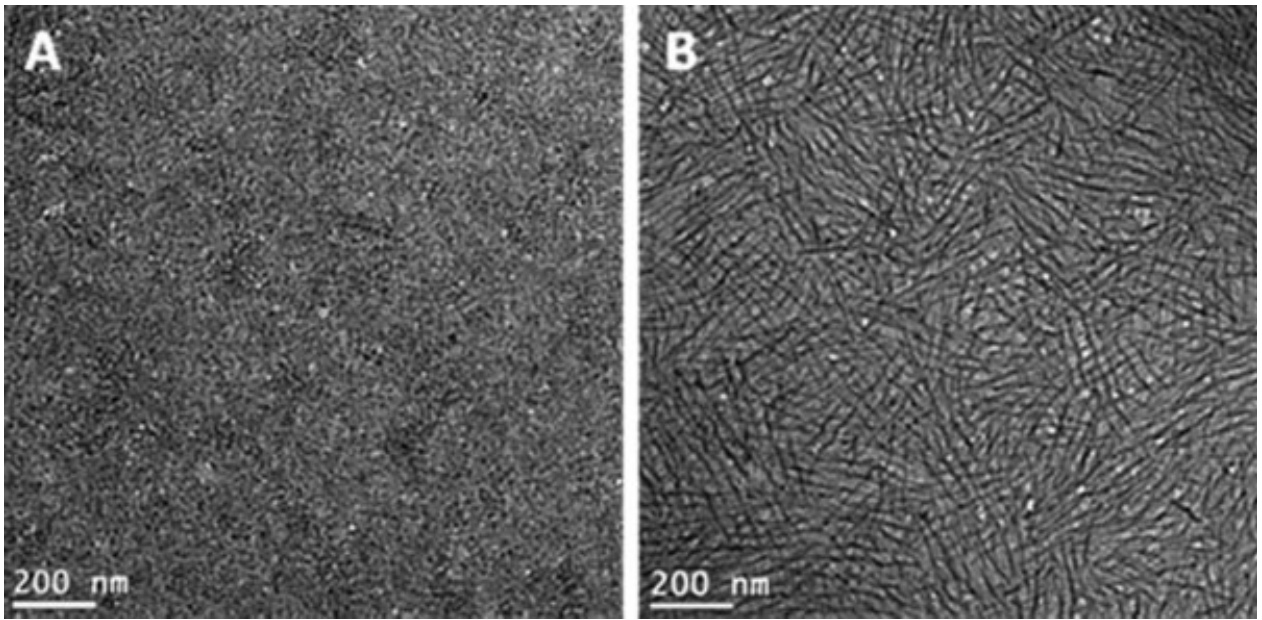

before thermal annealing (See Figure S4). Before annealing, the surface roughness is similar $(\mathrm{HcH} 63: 1.4 \mathrm{~nm}$; HcH77: 1.6 $\mathrm{nm})$ in such thin films $(22-25 \mathrm{~nm})$. The increase in the domain size may suggest a better molecular connectivity after thermal annealing. Nanowire-like morphology was not observed from the surface of these spin coated copolymer films.

\section{Field-Effect Transistors}

Field-effect charge transport in thin films of P3HT- $b$-P3cHT was investigated by fabricating and evaluating bottom-con- tact and bottom-gate field-effect transistors similar to our previous reports. ${ }^{23,52,53}$ Both $\mathrm{HcH} 63$ and $\mathrm{HcH} 77$ block copolymers showed typical hole-transport characteristics with clear current modulation as shown in Figure 7. $\mathrm{HcH} 77$ copolymer showed an average saturation region hole mobility of $1.9 \times 10^{-3} \mathrm{~cm}^{2} /$ Vs which was calculated from transfer curves [Fig. $7(\mathrm{C})]^{54} \mathrm{HcH} 63$ showed a lower mobility of 4.5 $\times 10^{-4} \mathrm{~cm}^{2} /$ Vs compared to that of $\mathrm{HcH} 77$. Current that flows through the channel of $\mathrm{HcH77}$ at on-state is 4- to 5fold larger compared to that of HcH63. Electrical parameters, such as the mobilities, on/off current ratios, and threshold
FIGURE 6 Tapping mode AFM topography and phase images of thin films of $\mathrm{HcH} 63$ $(\mathrm{A}, \mathrm{B})$ and $\mathrm{HcH} 77 \quad(\mathrm{C}, \mathrm{D})$ after thermal annealing at $150{ }^{\circ} \mathrm{C}$ for $1 \mathrm{~h}$.

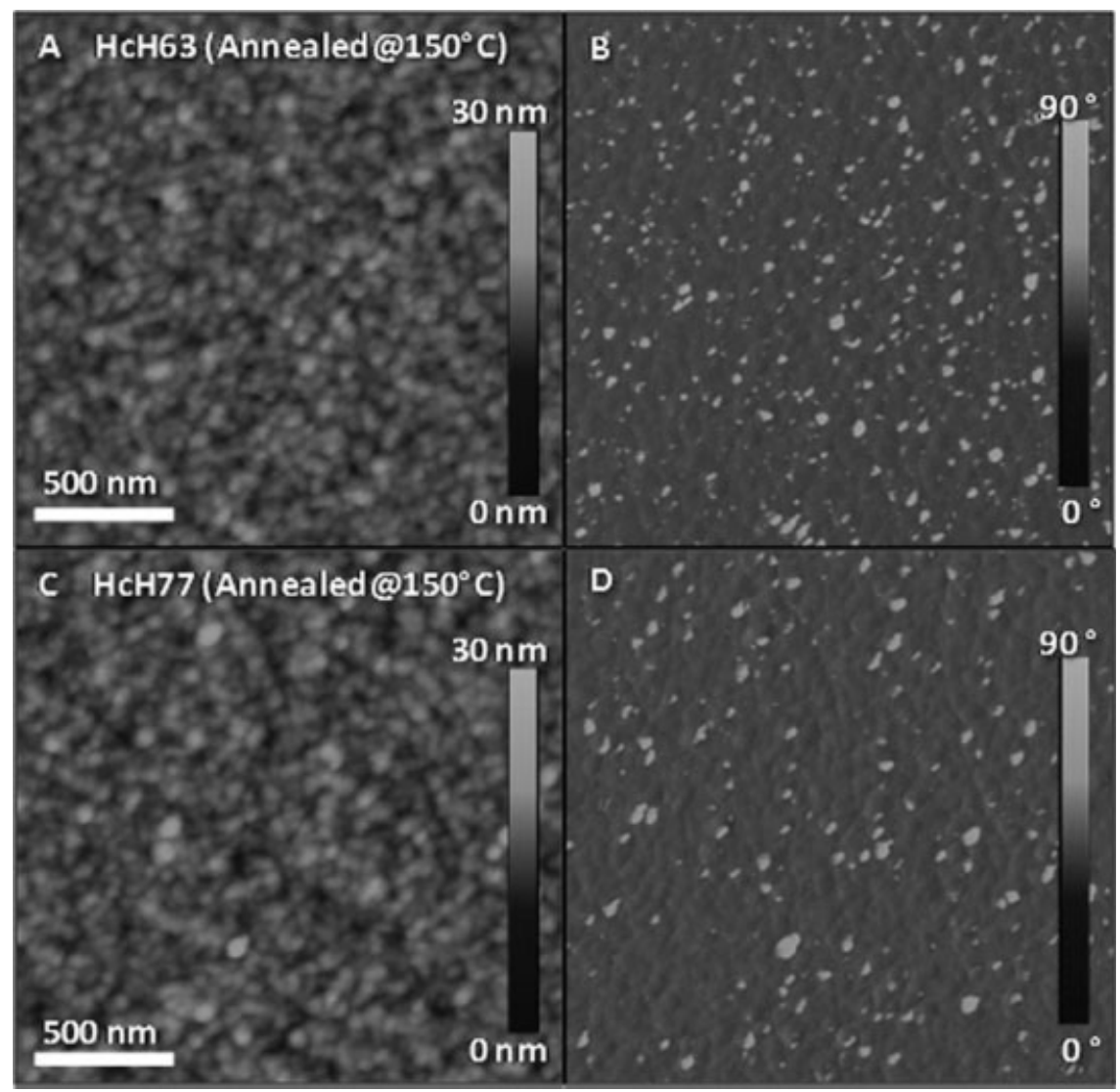




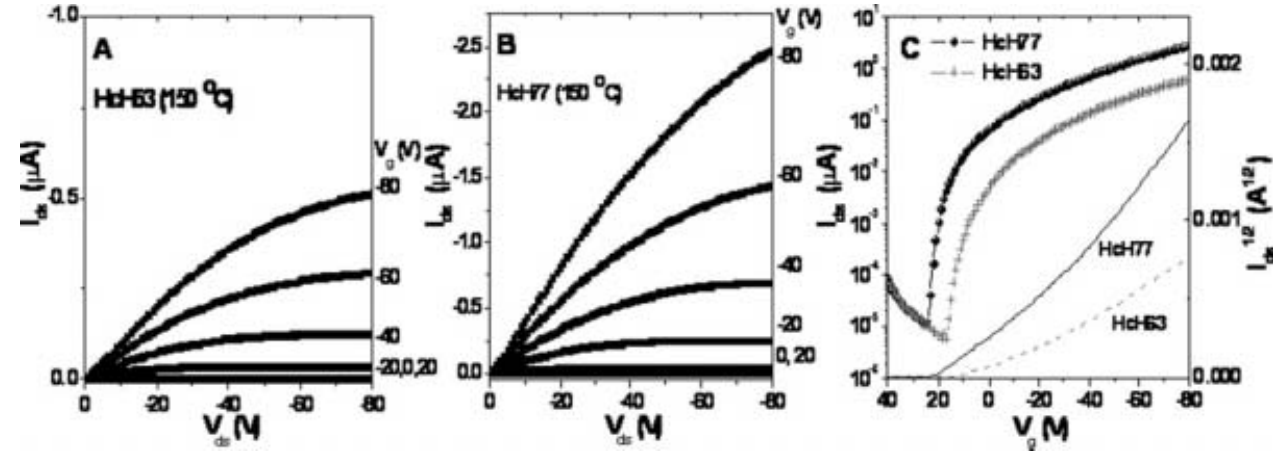

FIGURE 7 Output (A,B) and transfer $(C)$ characteristics of the $\mathrm{HcH} 63$ (A) and $\mathrm{HcH77}$ (B) fieldeffect transistors after thermal treatment at $150{ }^{\circ} \mathrm{C}$ for $1 \mathrm{~h}$. voltages of HcH63 and HcH77 thin films before and after thermal annealing are summarized in Table 1.

The difference in the charge-carrier mobility can be attributed to two different factors. First, the more bulky cyclohexyl side chain can lead to a larger $\pi$-stacking distance between polymer backbones. As shown in Figure 3(A), peaks corresponding to [020] plane in P3cHT is slightly shifted to lower $q$ values than in P3HT. Larger distance between $\pi$-orbitals prevents efficient charge transport along the $\pi$-stacking direction. As HcH63 copolymer has a higher ratio of P3cHT than P3HT blocks, charge transport in $\mathrm{HcH} 63$ may be limited by the P3cHT block compared to $\mathrm{HcH77}$. The other possible reason is that the molecular weight of $\mathrm{HcH} 63$ is smaller than that of HcH77. It has been reported that the molecular weight significantly affects the hole mobility in P3HT thin films. ${ }^{4,55,56}$ Longer polymer chains have more chances of interconnection between highly organized domains, and hence give higher charge-carrier mobility.

The carrier mobility of $\mathrm{HcH} 63$ is slightly decreased after thermal annealing at $150{ }^{\circ} \mathrm{C}$, while the mobility of $\mathrm{HcH} 77$ remains the same (Table 1 ). These phenomena can be correlated with temperature dependent WAXS results shown in Figure 4(A,C). HcH63 copolymer showed sudden disappearance of reflection peaks at $q \sim 3.7 \mathrm{~nm}^{-1}$ and $\sim 16 \mathrm{~nm}^{-1}$, characteristics of the crystalline P3HT domain, when the sample was heated from 120 to $180{ }^{\circ} \mathrm{C}$. The reduction of crystallinity can cause the decrease of hole mobility, as crystallinity plays a crucial role for high-mobility in P3HT devices. ${ }^{57}$ On the other hand, HcH77 copolymer did not show such sudden transition before $180-200{ }^{\circ} \mathrm{C}$. Therefore, the

TABLE 1 Field-Effect Charge Transport Properties of Poly(3-hexylthiophene)-b-poly(3-cyclohexylthiophene)

\begin{tabular}{|c|c|c|c|c|}
\hline Copolymer & $\begin{array}{l}\text { Thermal } \\
\text { Treatment }^{\mathrm{a}}\end{array}$ & $\begin{array}{l}\text { Hole Mobility } \\
\text { (cm²/Vs) }\end{array}$ & $I_{\text {on/off }}^{b, c}$ & $\begin{array}{l}V_{\mathrm{t}}^{\mathrm{b}} \\
\text { (V) }\end{array}$ \\
\hline \multirow[t]{2}{*}{$\mathrm{HcH} 63$} & - & $6.6 \times 10^{-4}$ & $10^{3}$ & 15 \\
\hline & $150^{\circ} \mathrm{C}$ for $1 \mathrm{~h}$ & $4.5 \times 10^{-4}$ & $10^{5}$ & -7 \\
\hline \multirow[t]{2}{*}{$\mathrm{HcH} 77$} & - & $1.9 \times 10^{-3}$ & $10^{3}$ & 23 \\
\hline & $150{ }^{\circ} \mathrm{C}$ for $1 \mathrm{~h}$ & $1.9 \times 10^{-3}$ & $10^{5}$ & -2 \\
\hline
\end{tabular}

\footnotetext{
a Thermal treatment was carried out under argon atmosphere.

b Average of 12 devices.

${ }^{c}$ Calculated from the ratio of the highest drain current to the lowest drain current in transfer curves.
}

measured hole mobility is the same before and after thermal annealing at $150{ }^{\circ} \mathrm{C}$.

Off-current of the devices was significantly decreased after thermal annealing, and therefore the on/off current ratio was increased from $10^{3}$ to $10^{5}$ in OFETs based on both HcH63 and HcH77 (Table 1). Threshold voltage also shifted toward negative value upon heat treatment. The increment of on/off ratios and the reduction of threshold voltages after annealing might originate from the removal of dopants (e.g., moisture) which unintentionally doped the films during the device fabrication process in ambient air.

\section{Photovoltaic Cells}

Bulk heterojunction (BHJ) solar cells based on the blends of $[6,6]$ phenyl- $\mathrm{C}_{71}$-butyric acid methyl ester $\left(\mathrm{PC}_{71} \mathrm{BM}\right)$ and the diblock copolymers, HcH63 and HcH77, were fabricated and evaluated. All BHJ solar cells had the basic device architecture, ITO/PEDOT:PSS/HcH:PC ${ }_{71} \mathrm{BM} / \mathrm{LiF} / \mathrm{Al}$ and were characterized under $100 \mathrm{~mW} / \mathrm{cm}^{2}$ AM1.5 solar irradiation in ambient air. To determine the optimal composition, $\mathrm{HcH} 77: \mathrm{PC}_{71} \mathrm{BM}$ blends at four different ratios (1:0.5, 1:0.75, $1: 1$ and 1:1.25, wt:wt) were investigated in BHJ solar cells. The current density-voltage characteristics of these $\mathrm{BHJ}$ devices with different $\mathrm{HcH} 77: \mathrm{PC}_{71} \mathrm{BM}$ blend compositions are shown in Figure 8. The corresponding photovoltaic

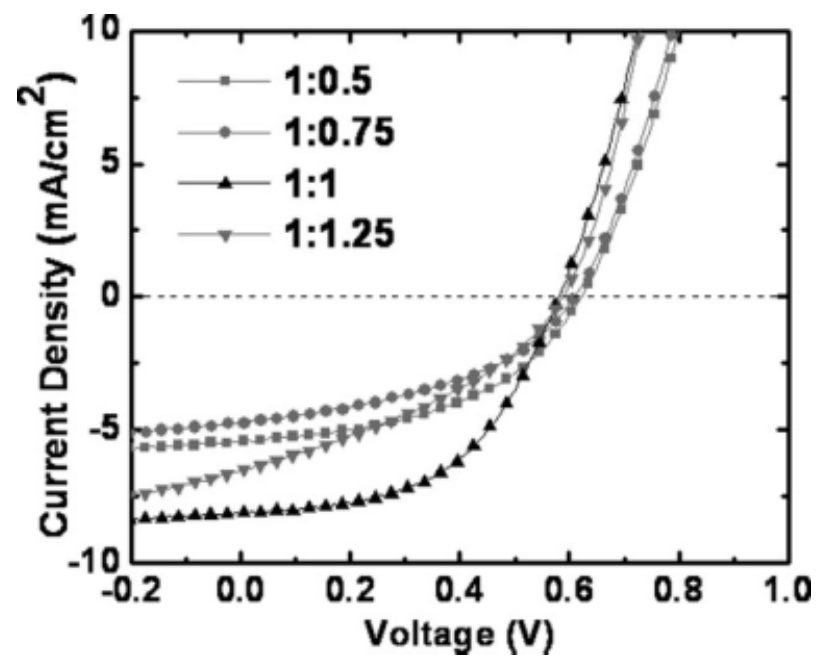

FIGURE 8 Current density-voltage curves of $\mathrm{HcH} 77: \mathrm{PC}_{71} \mathrm{BM}$ blend $\mathrm{BHJ}$ solar cells at various blend compositions. 


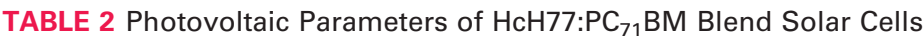

\begin{tabular}{llllllll}
\hline Polymer Blend & Composition & Thickness $(\mathrm{nm})$ & $V_{\mathrm{oc}}(\mathrm{V})$ & $J_{\mathrm{sc}}\left(\mathrm{mA} / \mathrm{cm}^{2}\right)$ & $\mathrm{FF}$ & $\mathrm{PCE}^{\mathrm{max}}(\%)$ & $\mathrm{PCE}^{\mathrm{avg}}(\%)$ \\
$\mathrm{HcH77:} \mathrm{PC}_{71} \mathrm{BM}$ & $1: 0.5$ & 105 & 0.62 & 5.82 & 0.45 & 1.63 & 1.52 \\
& $1: 0.75$ & 95 & 0.61 & 4.69 & 0.44 & 1.25 & 1.11 \\
& $1: 1$ & 90 & 0.58 & 8.14 & 0.52 & 2.45 & 2.37 \\
& $1: 1.25$ & 100 & 0.59 & 6.51 & 0.36 & 1.40
\end{tabular}

parameters, including open circuit voltage $\left(V_{\text {oc }}\right)$, short-circuit current density $\left(U_{\mathrm{sc}}\right)$, fill factor (FF), and power conversion efficiency (PCE) are shown in Table 2.

The thickness of four $\mathrm{HcH} 77: \mathrm{PC}_{71} \mathrm{BM}$ blend films was controlled in the range of 90-105 $\mathrm{nm}$ after being dried in vacuum. The $0.58-0.62 \mathrm{~V}$ open circuit voltages $\left(V_{\text {oc }}\right)$ observed in the series of HcH77-based BHJ solar cells are very similar to the $0.5-0.6 \mathrm{~V}$ typically seen in solar cells based on P3HT. ${ }^{31,32}$ The short-circuit current density and fill factor were not ideal, which may arise from the limitations of charge transport in the blend films. The best average PCE $(2.37 \%)$ was

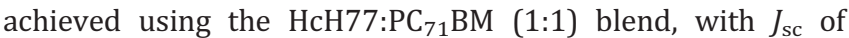
$8.14 \mathrm{~mA} / \mathrm{cm}^{2}, V_{\text {oc }}$ of $0.58 \mathrm{~V}$, and quite high $\mathrm{FF}$ of 0.52 . This result in Table 2 suggests that a $1: 1$ (wt:wt) ratio of $\mathrm{HcH}: \mathrm{PC}_{71} \mathrm{BM}$ blends is the best composition for the $\mathrm{BHJ}$ solar cells, which is in line with the $1: 1$ best ratio found in the P3HT: $\mathrm{PC}_{71} \mathrm{BM}$ blend $\mathrm{BHJ}$ solar cells reported in the literature. ${ }^{31,58,59}$ Thus, we believe the $1: 1$ ratio is the optimal ratio for balanced charge transport in $\mathrm{HcH}: \mathrm{PC}_{71} \mathrm{BM}$ blend $\mathrm{BHJ}$ solar cells, with the limitation of charge transport arising from the relatively low mobility of holes. ${ }^{60}$

The HcH63:PC ${ }_{71} \mathrm{BM}$ and $\mathrm{HcH77}: \mathrm{PC}_{71} \mathrm{BM}$ (1:1) blend solar cells under four different post-treatment conditions were tested in air. The four different conditions are: (1) dried in glovebox, (2) film aging in a Petri dish until color changes and then vacuum dried at $60{ }^{\circ} \mathrm{C}$, (3) film aging in a Petri dish until color changes and thermally annealed at $110{ }^{\circ} \mathrm{C}$ for $5 \mathrm{~min}$, and (4) film aging in a Petri dish for $30 \mathrm{~min}$ and thermally annealed at $110{ }^{\circ} \mathrm{C}$ for $30 \mathrm{~min}$. The photovoltaic parameters of $\mathrm{BHJ}$ solar cells based on $\mathrm{HcH} 63: \mathrm{PC}_{71} \mathrm{BM}$ and $\mathrm{HcH77}: \mathrm{PC}_{71} \mathrm{BM}$ (1:1) blends under these four different posttreatment conditions are summarized in Table 3 .
HcH63: $\mathrm{PC}_{71} \mathrm{BM}$ blend devices achieved a maximum PCE of $1.20 \%$ under Condition 2, processed with film aging and vacuum drying. Similarly, $\mathrm{HcH77}: \mathrm{PC}_{71} \mathrm{BM}$ blend devices gave a maximum PCE of $2.45 \%$ under Condition 2 (Table 3). The difference in photovoltaic performances between HcH63 and HcH77 devices may be attributed to the molecular weight and the percentage of the P3cHT block in the diblock copolymer. As mentioned earlier, the cyclohexyl rings are more "bulky" compared with linear hexyl chains, and as a result, the close packing of polythiophene backbones along the (020) direction ( $\pi-\pi$ stacking direction) is affected and is slightly larger than that of P3HT. This explains the observed phenomena that as the percentage of P3cHT block decreases, the charge-carrier mobility increases. Meanwhile, the steric hindrance caused by the "bulky" cyclohexyl side-groups is likely to prevent the close contact between polymer backbones and $\mathrm{PC}_{71} \mathrm{BM}$ molecules, resulting in reduction of exciton dissociation. As the $V_{\text {oc }}$ values (0.58-0.64 V) are very similar in both BHJ devices based on HcH63 and HcH77 in Table 3, the overall low PCEs seen in HcH63: $\mathrm{PC}_{71} \mathrm{BM}$ blend solar cells are greatly affected by the reduction of $J_{\mathrm{sc}}$ and $\mathrm{FF}$ and a lower hole mobility of HcH63.

The processing Condition 2 (film aging and then dried in vacuum) seems to be the optimal post-treatment for BHJ devices based on $\mathrm{HcH} 63$ and $\mathrm{HcH77}$, without further thermal annealing. Compared with the directly dried devices (Condition 1), the increase of PCE seen in BHJ devices (Condition 2) is largely attributed to the increase of $J_{\mathrm{sc}}$, while $\mathrm{FF}$ and $V_{\mathrm{oc}}$ is almost identical in both $\mathrm{HcH} 63: \mathrm{PC}_{71} \mathrm{BM}$ and $\mathrm{HcH} 77: \mathrm{PC}_{71} \mathrm{BM}$ blend devices (Table 3). Such enhancement in polymer solar cell performance during "slow drying" process ${ }^{31}$ has been reported, when the molecular order of polymers is improved. ${ }^{61}$ The

TABLE 3 Photovoltaic Parameters of HcH63-Based and HcH77-Based Solar Cells

\begin{tabular}{|c|c|c|c|c|c|c|c|}
\hline Polymer Blend ${ }^{a}$ & Condition $^{\mathrm{b}}$ & Thickness (nm) & $V_{\mathrm{oc}}(\mathrm{V})$ & $J_{\mathrm{sc}}\left(\mathrm{mA} / \mathrm{cm}^{2}\right)$ & $\mathrm{FF}$ & $\mathrm{PCE}^{\max }(\%)$ & $\mathrm{PCE}^{\text {avg }}(\%)$ \\
\hline \multirow[t]{4}{*}{$\mathrm{HcH} 63: \mathrm{PC}_{71} \mathrm{BM}$} & 1 & 105 & 0.64 & 4.24 & 0.32 & 0.86 & 0.82 \\
\hline & 2 & 110 & 0.61 & 6.18 & 0.32 & 1.20 & 1.17 \\
\hline & 3 & 105 & 0.62 & 3.85 & 0.30 & 0.73 & 0.71 \\
\hline & 4 & 120 & 0.63 & 3.71 & 0.32 & 0.74 & 0.62 \\
\hline \multirow[t]{4}{*}{$\mathrm{HcH} 77: \mathrm{PC}_{71} \mathrm{BM}$} & 1 & 90 & 0.63 & 6.94 & 0.51 & 2.22 & 2.09 \\
\hline & 2 & 90 & 0.58 & 8.14 & 0.52 & 2.45 & 2.37 \\
\hline & 3 & 90 & 0.63 & 7.45 & 0.47 & 2.18 & 1.96 \\
\hline & 4 & 85 & 0.62 & 7.76 & 0.50 & 2.41 & 2.22 \\
\hline
\end{tabular}

a Polymer:PC ${ }_{71} \mathrm{BM}=1: 1$ (wt:wt) for all blends.

${ }^{b}$ Condition 1: open dried in glovebox; Condition 2: film aging in a Petri dish until color changes and vacuum dried at $60{ }^{\circ} \mathrm{C}$; Condition 3: film aging in a Petri dish until color changes and thermally annealed at $110{ }^{\circ} \mathrm{C}$ for $5 \mathrm{~min}$. Condition 4: film aging in a Petri dish for $30 \mathrm{~min}$ and thermally annealed at $110{ }^{\circ} \mathrm{C}$ for $30 \mathrm{~min}$. 


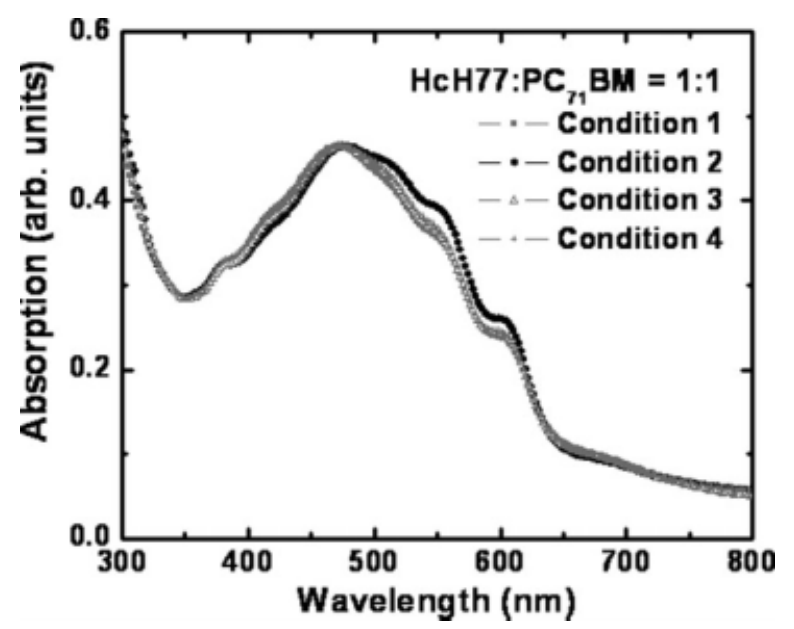

FIGURE 9 UV-visible absorption spectra of $\mathrm{HcH77:PC}{ }_{71} \mathrm{BM}(1: 1)$ blend films at different post-treatment conditions.

improved vibronic shoulders around 560 and $600 \mathrm{~nm}$ in $\mathrm{HcH77}$ as observed in the absorption spectra shown in Figure 9, suggest an improved crystallinity in the blend films under Condition 2. Similar enhanced absorption in $\mathrm{HcH} 63: \mathrm{PC}_{71} \mathrm{BM}$ blend films is also seen in Figure S5.

In Figure 10, the AFM images of $\mathrm{HcH} 77: \mathrm{PC}_{71} \mathrm{BM}$ blend films show that the average surface roughness $\left(R_{\mathrm{a}}\right)$ increased from $1.46 \mathrm{~nm}$ (Condition 1) to $3.95 \mathrm{~nm}$ (Condition 2). Also, the corresponding phase image of the $\mathrm{HcH} 77: \mathrm{PC}_{71} \mathrm{BM}$ blend film in Fig- ure 10(D) shows more distinct phase contrast, an indication of increased order and crystallinity in the blend films. In the case of the HcH63: $\mathrm{PC}_{71} \mathrm{BM}$ blend films, the $R_{\mathrm{a}}$ value changed from $1.68 \mathrm{~nm}$ (Condition 1) to $2.04 \mathrm{~nm}$ (Condition 2; See Figure S6). During the "slow drying" process (Condition 2), both vertical and horizontal diffusion of $\mathrm{PC}_{71} \mathrm{BM}$ molecules in polymer films can take place and these two diffusions can be responsible for the increase in surface roughness. The bulky cyclohexyl side chains are more rigid and can affect the diffusion of $\mathrm{PC}_{71} \mathrm{BM}$ molecules, compared with the flexible linear hexyl side chains. As the solvent evaporates slowly, diffusion of $\mathrm{PC}_{71} \mathrm{BM}$ molecules takes place and the surface roughness significantly increases, combined with enhanced crystallinity in $\mathrm{HcH} 77: \mathrm{PC}_{71} \mathrm{BM}$ films, translating into a higher power conversion efficiency.

TEM imaging was also performed on the $\mathrm{HcH}: \mathrm{PC}_{71} \mathrm{BM}$ blend films peeled directly from the devices, shown in Figure 11 and Figure S7. All films show worm-like nanoscale morphology but the phase contrast between the polymer and $\mathrm{PC}_{71} \mathrm{BM}$ is better under Condition 2. It should be noted that, in HcH77 devices, the nanowires from solution-phase self-assembly of block copolymers remained intact in the blend films treated under Condition 2, while the nanoscale features are not clear after drying in the glovebox (Condition 1). As the crystalline nanowires contribute to the higher hole mobility, improved exciton dissociation through electrically interconnected pathways, and enhanced performance in photovoltaic devices, $^{50,51}$ the nanostructures formed under Condition 2 may be superior than that obtained following Condition 1.
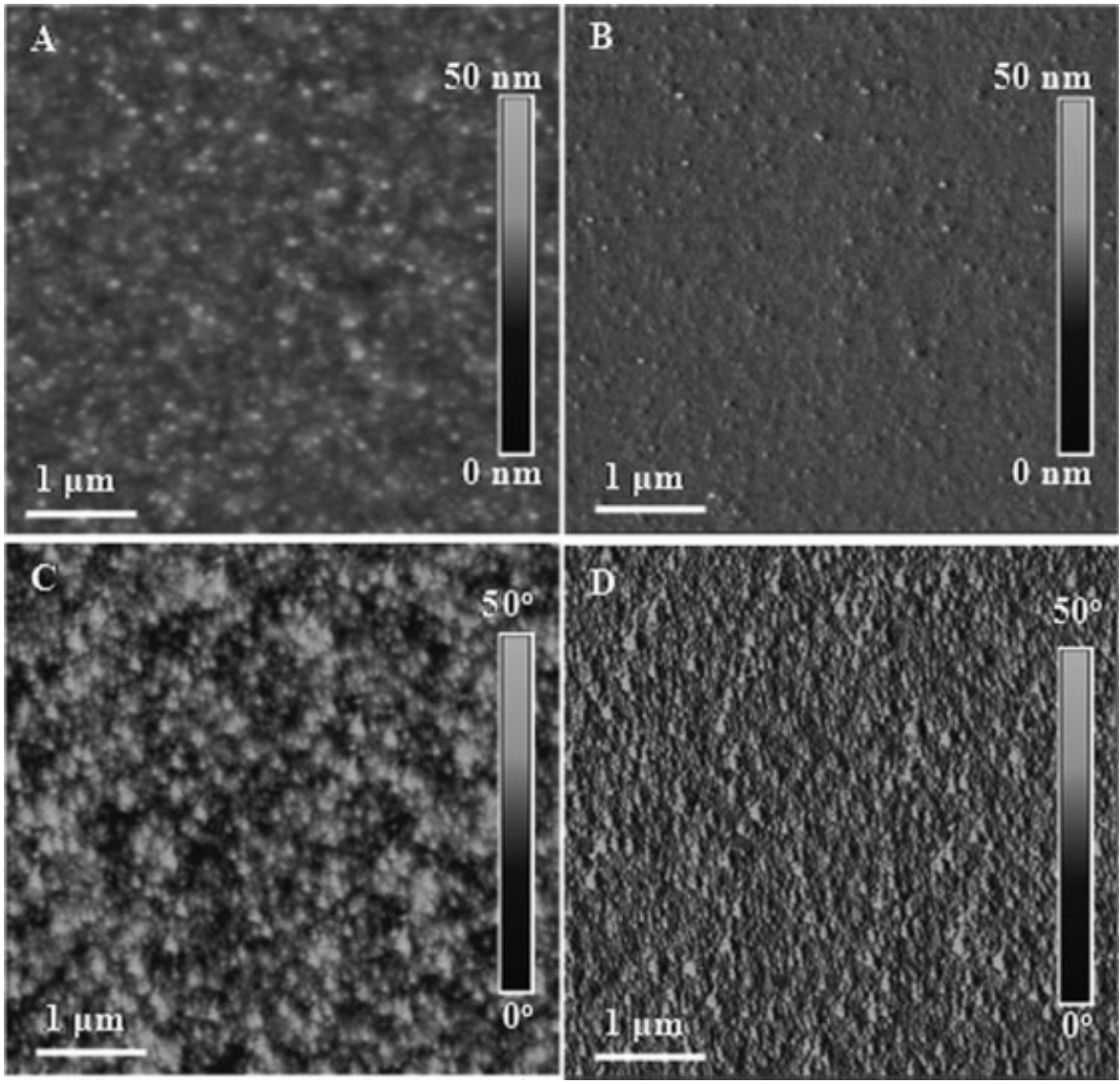

FIGURE 10 AFM images of $\mathrm{HcH77}$ : $\mathrm{PC}_{71} \mathrm{BM}(1: 1)$ blend films under Condition $1(A, B)$ and Condition $2(C, D)$. 
FIGURE 11 TEM images of thin films of $\mathrm{HcH77:PC} \mathrm{P}_{71} \mathrm{BM} \quad(1: 1)$ blends under different conditions: (A) Condition 1, open dried; (B) Condition 2, film aging and vacuum dried.
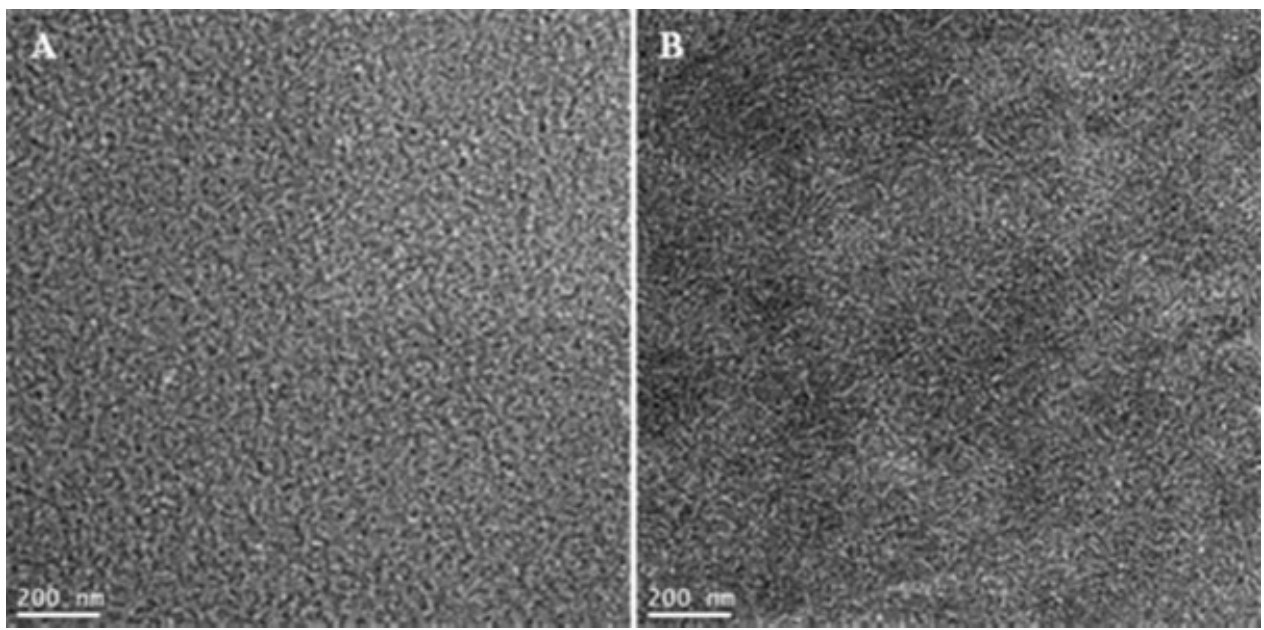

Based on selected area electron diffraction (SAED) measurement, it is found that the crystallinity of both polymers and $\mathrm{PC}_{71} \mathrm{BM}$ is improved with film aging (See Figure S8). These phenomena agree well with the previously discussed results of UV-visible absorption in Figure 9 and AFM and TEM morphology, and might account for the enhancement of photovoltaic performance under Condition 2 .

Surprisingly, the commonly applied thermal annealing does not help to increase the performance of $\mathrm{HcH}: \mathrm{PC}_{71} \mathrm{BM}$ solar cells. When comparing BHJ devices obtained under Conditions 2 and 3 , the thermal annealing process does not improve the photovoltaic performance (Table 3). $J_{\mathrm{sc}}$ in both $\mathrm{HcH}: \mathrm{PC}_{71} \mathrm{BM}$ blends is reduced, and $38 \%$ and $8 \%$ reductions are observed in $\mathrm{HcH} 63$ and $\mathrm{HcH77}$ devices, respectively. During thermal annealing, the fast evaporation of residual solvents allows fast vertical diffusion of $\mathrm{PC}_{71} \mathrm{BM}$; the "bulky" nature of cyclohexyl ring facilitates this diffusion, and the phase separation in P3HT- $b$-P3cHT/PC ${ }_{71} \mathrm{BM}$ blends can be stronger than P3HT/ $\mathrm{PC}_{71} \mathrm{BM}$ blends after heat treatments. With longer film aging time (Condition 4), the residual solvent was nearly completely removed, leaving the sample in a solid state with high crystalline content. Thus, the vigorous heating process does not cause severe vertical phase-separation in that case.

\section{CONCLUSIONS}

We have synthesized regioregular poly(3-hexylthiophene)- $b$ poly(3-cyclohexylthiophene) $\left(M_{\mathrm{w}}=155,500-210,800 \mathrm{~g} / \mathrm{mol}\right.$, PDI $=1.45-1.57$ ) and investigated their morphology in the solid state, together with the corresponding electronic, and optoelectronic properties. WAXS and SAXS studies confirmed that the two P3HT- $b$-P3cHT samples in the melt phase assemble into a microphase separated structure with two crystalline domains (length scale $\sim 17.0-21.7 \mathrm{~nm}$ ) reflecting the two different side chains. Two distinct $d_{100}$ values of 1.40 and 1.69 $\mathrm{nm}$ are reflecting the interlayer stacking distance in the crystalline P3cHT and P3HT domains, respectively.

The use of P3HT- $b$-P3cHT as a p-type semiconductor in organic electronics was evaluated by fabricating bottom-contact field-effect transistors and the hole mobility was found to be $4.5 \times 10^{-4}$ and $1.9 \times 10^{-3} \mathrm{~cm}^{2} /$ Vs for HcH63 and
HcH77, respectively. Unlike the parent homopolymer, P3HT, the mobility remains the same after thermal annealing due to the introduction of the more robust P3cHT block. Bulk

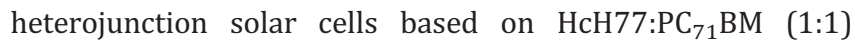
blend films were found to have a $2.45 \%$ power conversion efficiency under $100 \mathrm{~mW} / \mathrm{cm}^{2}$ AM1.5 sunlight illumination in ambient air. The slow-drying process (Condition 2) allows the rigid polythiophene chains to self-organize into crystalline structure in the thin films whereas the additional thermal annealing does not further enhance the photovoltaic performance. Our results suggest that block copoly(3-alkylthiophene)s are promising p-type semiconductors, which can be processed without need of additional thermal annealing during device fabrication for organic electronics.

This work was supported by the Department of Energy, Basic Energy Sciences (DE-FG02-07ER46467) and the NSF (DMR0805259 and DMR-0120967). Part of this work was conducted at the University of Washington NanoTech User Facility, a member of the NSF National Nanotechnology Infrastructure Network (NNIN). C.L. and R.M. thank the Swiss National Science Foundation for financial support.

\section{REFERENCES AND NOTES}

1 Babel, A.; Jenekhe, S. A. J Phys Chem B 2003, 107, 1749-1754.

2 Babel, A.; Jenekhe, S. A. Macromolecules 2004, 37, 9835-9840.

3 Alam, M. M.; Tonzola, C. J.; Jenekhe, S. A. Macromolecules 2003, 36, 6577-6587.

4 Zen, A.; Saphiannikova, M.; Neher, D.; Asawapirom, U.; Scherf, U. Chem Mater 2005, 17, 781-786.

5 Sary, N.; Mezzenga, R.; Brochon, C.; Hadziioannou, G.; Ruokolainen, J. Macromolecules 2007, 40, 3277-3286.

6 Jenekhe, S. A.; Chen, X. L. Science 1998, 279, 1903-1907.

7 Alam, M. M.; Jenekhe, S. A. Macromol Rapid Commun 2006, 27, 2053-2059.

8 Zhang, X.; Kale, D. M.; Jenekhe, S. A. Macromolecules 2002, 35, 382-393. 
9 Chen, X. L.; Jenekhe, S. A. Science 1999, 283, 372-375.

10 Chen, X. L.; Jenekhe, S. A. Macromolecules 2000, 33, $4610-4612$.

11 Liu, J.; Sheina, E.; Kowalewski, T.; McCullough, R. D. Angew Chem Int Ed 2002, 41, 329-332.

12 Leclére, Ph.; Calderone, A.; Marsitzky, D.; Francke, V.; Geerts, Y.; Müllen, K.; Brédas, J.-L.; Lazzaroni, R. Adv Mater 2000, 12, 1042-1046.

13 Stalmach, U.; de Boer, B.; Videlot, C.; Van Hutten, P. F.; Hadziioannou, G. J Am Chem Soc 2000, 122, 5464-5472.

14 Olsen, B. D.; Segalman, R. A. Macromolecules 2005, 38, 10127-10137.

15 Sary, N.; Brochon, C.; Hadziioannou, G.; Mezzenga, R. Eur Phys J E 2007, 24, 379-384.

16 Chen, X. L.; Jenekhe, S. A. Macromolecules 1996, 29, 6189-6192.

17 Scherf, U.; Gutacker, A.; Koenen, N. Acc Chem Res 2008, 41, 1086-1097.

18 Liang, Y.; Wang, H.; Yuan, S.; Lee, Y.; Gan, L.; Yu, L. J Mater Chem 2007, 17, 2183-2194.

19 Plank, H.; Güntner, R.; Scherf, U.; List, E. J. W. Adv Funct Mater 2007, 17, 1093-1105.

20 Tu, G.; Li, H.; Forster, M.; Heiderhoff, R.; Balk, L. J.; Scherf, U. Macromolecules 2006, 39, 4327-4331.

21 Rubatat, L.; Kong, X.; Jenekhe, S. A.; Ruokolainen, J.; Hojeij, M.; Mezzenga, R. Macromolecules 2008, 41, 1846-1852.

22 Sary, N.; Rubatat, L.; Brochon, C.; Hadziioannou, G.; Ruokolainen, J.; Mezzenga, R. Macromolecules 2007, 40, 6990-6997.

23 Zhu, Y.; Champion, R. D.; Jenekhe, S. A. Macromolecules 2006, 39, 8712-8719.

24 Yamamoto, T.; Koizumi, T. Polymer 2007, 48, 5449-5472.

25 Leclére, Ph.; Surin, M.; Brocorens, P.; Cavallini, M.; Biscarini, F.; Lazzaroni, R. Mater Sci Eng R 2006, 55, 1-56.

26 Reddinger, J. L.; Reynolds, J. R. Adv Polym Sci 1999, 145, 57-122.

27 McCullough, R. D.; Lowe, R. D.; Jayaraman, M.; Anderson, D. L. J Org Chem 1993, 115, 904-912.

28 Chen, T.-A.; Wu, X.; Rieke, R. D. J Am Chem Soc 1995, 117, 233-244.

29 Bao, Z.; Dobabalapur, A.; Lovinger, A. J. Appl Phys Lett 1996, 69, 4108-4110.

30 Babel, A.; Jenekhe, S. A. Synth Met 2005, 148, 169-173.

31 Li, G.; Shrotriya, V.; Huang, J. S.; Yao, Y.; Moriarty, T.; Emery, K.; Yang, Y. Nat Mater 2005, 4, 864-868.

32 Ma, W. L.; Yang, C. Y.; Gong, X.; Lee, K.; Heeger, A. J. Adv Funct Mater 2005, 15, 1617-1622.

33 Somanathan, N.; Wegner, G. Acta Polym 1999, 50, 145-150.

34 Saxena, V.; Shirodkar, V. S. J Appl Polym Sci 2000, 77, 1051-1055.

35 Saxena, V.; Prakash, R. Polym Bull 2000, 45, 267-274.

36 Theander, M.; Inganäs, O.; Mammo, W.; Olinga, T.; Svensson, M.; Anderson, M. R. J Phys Chem B 1999, 103, 7771-7780.
37 Anderson, M. R.; Berggren, M.; Gustafsson, G.; Hjertberg, T.; Inganäs, O.; Wennerström, O. Synth Met 1995, 71, 2183-2184.

38 Zhang, Y.; Tajima, K.; Hirota, K.; Hashimoto, K. J Am Chem Soc 2008, 130, 7812-7813.

39 Yokozawa, T.; Adachi, I.; Miyakoshi, R.; Yokoyama, A. High Perform Polym 2007, 19, 684-699.

40 Ohshimizu, K.; Ueda, M. Macromolecules 2008, 41, 5289-5294.

41 Wu, P. T.; Ren, G.; Li, C.; Mezzenga, R.; Jenekhe, S. A. Macromolecules 2009, 42, 2317-2320.

42 Heeny, M.; Zhang, W.; Duffy, W.; McCulloch, I.; Koller, G. Merck Co. World Patent Application, WO2007/059838, 2007.

43 lovu, M. C.; Sheina, E. E.; Gil, R. R.; McCullough, R. D. Macromolecules 2005, 38, 8649-8656.

44 Liu, J.; Loewe, R. S.; McCullough, R. D. Macromolecules 1999, 32, 5777-5785.

45 Lee, Y.; Fukukawa, K.-I.; Bang, J.; Hawker, C. J.; Kim, J. K. J Polym Sci Part A: Polym Chem 2008, 46, 8200-8205.

46 Zhang, S.; Guo, Y.; Fan, J.; Liu, Y.; Chen, H.-Y.; Yang, G.; Zhan, X.; Liu, Y.; Li, Y.; Yang, Y. J Polym Sci Part A: Polym Chem 2009, 47, 5498-5508.

47 Wu, P.-T.; Xin, H.; Kim, F. S.; Ren, G.; Jenekhe, S. A. Macromolecules 2009, 42, 8817-8826.

48 Ouhib, F.; Hiorns, R. C.; De Bettignies, R.; Bailly, S.; Desbrières, J.; Dargon-Lartigau, C. Thin Solid Films 2008, 516, 7199-7204.

49 Samitsu, S.; Shimomura, T.; Heike, S.; Hashizume, T.; Ito, K. Macromolecules 2008, 41, 8000-8010.

50 Xin, H.; Kim, F. S.; Jenekhe, S. A. J Am Chem Soc 2008, $130,5424-5425$.

51 Xin, H.; Ren, G.; Kim, F. S.; Jenekhe, S. A. Chem Mater 2008, 20, 6199-6207.

52 Babel, A.; Jenekhe, S. A. J Am Chem Soc 2003, 125, 13656-13657.

53 Kim, F. S.; Guo, X.; Watson, M. D.; Jenekhe, S. A. Adv Mater 2009; DOI: 10.1002/adma.200901819.

54 Horowitz, G. Adv Mater 1998, 10, 365-377.

55 Kline, R. J.; McGehee, M. D.; Kadnikova, E. N.; Liu, J. S.; Fréchet, J. M. J.; Toney, M. F. Macromolecules 2005, 38, 3312-3319.

56 Zen, A.; Saphiannikova, M.; Neher, D.; Grenzer, J.; Grigorian, S.; Pietsch, U.; Asawapirom, U.; Janietz, S.; Scherf, U.; Lieberwirth, I.; Wegner, G. Macromolecules 2006, 39, 2162-2171.

57 Sirringhaus, H.; Brown, P. J.; Friend, R. H.; Nielsen, M. M.; Bechgaard, K.; Langeveld-Voss, B. M. W.; Spiering, A. J. H.; Janssen, R. A. J.; Meijer, E. W.; Herwig, P.; de Leeuw, D. M. Nature 1999, 401, 685-688.

58 Chirvase, D.; Parisi, J.; Hummelen, J. C.; Dyakonov, V. Nanotechnology 2004, 15, 1317-1323.

59 Shrotriya, V.; Ouyang, J.; Tseng, R. J.; Li, G.; Yang, Y. Chem Phys Lett 2005, 411, 138-143.

60 Brabec, C. J. Sol Energy Mater Sol Cells 2004, 83, 273-292.

61 Li, G.; Yao, Y.; Yang, H.; Shrotriya, V.; Yang, G.; Yang, Y. Adv Funct Mater 2007, 17, 1636-1644. 